\title{
Turbulent Flow in Constricted Blood Vessels \\ Quantification of Wall Shear Stress Using Large Eddy Simulation
}

\author{
Roland Gårdhagen
}

Division of Applied Thermodynamics and Fluid Mechanics Department of Management and Engineering Linköping University 


\section{Turbulent Flow in Constricted Vessels Quantification of Wall Shear Stress Using Large Eddy Simulation}

Linköping Studies in Science and Technology

Dissertations, No. 1558

Distributed by:

Department of Management and Engineering

Linköping University

SE-581 83, Sweden

Printed by:

LiuTryck, Linköping, Sweden

ISBN 978-91-7519-473-8

ISSN 0345-7524

(c) 2013 Roland Gårdhagen

No part of this publication may be reproduced, stored in a retrieval system, or be transmitted, in any form or by any means, electronic, mechanic, photocopying, recording, or otherwise, without prior permission of the author.

Cover: Pipe flow becomming turbulent after a constriction. Streamlines, wall shear stress on the surface, and vorticity in three cross sections. 


\section{Abstract}

The genesis of atherosclerosis has previously been shown to be affected by the frictional load from the blood on the vessel wall, called the wall shear stress (WSS). Assessment of WSS can therefore provide important information for diagnoses, intervention planning, and follow-up. Calculation of WSS requires highresolved velocity data from the vessel, which in turn can be obtained using computational fluid dynamics (CFD). In this work large eddy simulation LES was successfully used to simulate transitional flow in idealized as well as subject specific vessel models. It was shown that a scale resolving technique is to prefer for this application, since much valuable information otherwise is lost. Besides, Reynolds-Averaged Navier-Stokes (RANS) models have generally failed to predict this type of flow.

Non-pulsating flows of Reynolds numbers up to 2000 in a circular constricted pipe showed that turbulence is likely to occur in the post-stenotic region, which resulted in a complex WSS pattern characterized by large spatial as well temporal fluctuations in all directions along the wall. Time averaged streamwise WSS was relatively high, while time averaged circumferential WSS was low, meaning that endothelial cells in that region would be exposed to oscillations in a stretched state in the streamwise direction and in a relaxed state in the circumferential direction.

Since every vessel is unique, so is also its WSS pattern. Hence the CFD simulations must be done in subject specific vessel models. Such can be created from anatomical information acquired with magnetic resonance imaging (MRI). MRI can also be used to obtain velocity boundary conditions for the simulation. This technique was used to investigate pulsating flow in a subject specific normal human aorta. It was shown that even the flow in healthy vessels can be very disturbed and turbulence like, and even for this case large WSS variations were seen. It was also shown that regions around branches from the aorta, known to be susceptible for atherosclerosis, were characterized by high time averaged WSS and high oscillatory shear index.

Finally, the predictive capability of CFD was investigated. An idealized model of a human aorta with a coarctation and post-stenotic dilatation was studied before and after a possible repair of the constriction. The results suggested that 
small remaining abnormalities in the geometry may deteriorate the chances for a successful treatment. Also, high values of shear rate and Reynolds stresses were found in the dilatation after the constriction, which previous works have shown means increased risk for thrombus formation and hemolysis. 


\section{Populärvetenskaplig beskrivning}

Studier har visat på samband mellan vissa hjärt- kärlsjukdomar, t.ex. ateroskleros (åderförkalkning), och rent strömningstekniska fenomen såsom friktionen från blodet på kärlväggen, ofta kallad väggskjuvspänning, eller på engelska wall shear stress (WSS). Detta öppnar för användning av numeriska strömningssimuleringar, även kallat computational fluid dynamics (CFD), för analys av rådande förhållanden i ett sjukligt kärl, och prediktiv utvärdering av möjliga alternativa ingrepp för att finna en optimal lösning för varje patient.

Patientspecifik information samlas in med magnetresonanstomografi (MRI), anatomiska data används för att skapa en modell av kärlet och hastighetsmätningar används som randvillkor för simuleringarna. Vid förträngningar i blodkärlen blir strömningen ofta turbulent, vilket gör att den karaktäriseras av snabba förändringar i hastighet, tryck mm som kräver mycket hög spatiell och temporal upplösning vid simulering. I detta arbete används en simuleringsmetod kallad large eddy simulation (LES), med vilken de större turbulenta rörelserna löses upp (beräknas) medan de mindre modelleras. I sammanhanget är rörelser av storleksordningen $0,1 \mathrm{~ms}$ och $0,1 \mathrm{~mm}$ att betrakta som större.

Strömning med Reynolds tal upp till $2000 \mathrm{i}$ ett cirkulärt rör med en förträning simulerades och jämfördes med experimentella data. Resultaten visade att storleken på störningar i inloppet kan användas för att delvis kontrollera den turbulenta strömningen som uppstår efter förträngningen. Det visade sig också att väggskjuvspänningen påverkades kraftigt av turbulensen och uppvisade kraftiga fluktuationer såväl spatiellt som temporalt.

Pulserande strömning i en individspecifik aorta visade att flödet även i friska kärl kan vara kraftigt stört och turbulensliknande. Även här sågs påtagliga variationer i väggskjuvspänning och områden med både kraftigt oscillerande WSS och WSS med högt tidsmedelvärde identifierades runt avledningar från aorta; områden som ofta drabbas av ateroskleros. En idealiserad aortamodell med förträngning och efterföljande dilatation studerades före och efter ett ingrepp där förträngingen avlägsnades. Här visade resultaten att även tillsynes små återstående defekter hos geometrin kan påverka det långsiktiga resultatet negativt. Vidare kan bl.a. turbulensen leda till blodproppar och att blodets beståndsdelar skadas. 



\section{Acknowledgments}

First, I want to thank my main supervisor Prof. Matts Karlsson, unending source of new ideas, for all support, inspiration, and memorable events during this time. My second supervisor Prof. Toste Länne, is also greatly acknowledged. A special thank you and mark of honor goes to Prof. em. Dan Loyd for all encouragement and feedback during the work, particularly during the last part.

A big thank you to Ph.D. Fredrik Carlsson for all advices and other contributions during the work. A big thank you also to Ph.D. Jonas Lantz and Ph.D. Johan Renner for all discussions, contributing work, and inspiring conference visits.

For all enthusiasm and contributions to course development, which went on parallel to the thesis work, vielen Dank Jörg Schminder. I am also very grateful to my colleagues at the Division of Applied Thermodynamics and Fluid Mechanics, former and present, for all collaboration. Either as part of the research or as refreshing activities beside.

National Supercomputer Centre is acknowledged for all technical support with the calculations. All people at Center for Medical Image Science and Visualization (CMIV) and Department of Medicine and Care, who have shared their great knowledge in medicine, are acknowledged.

To my family and friends - despite long (working) periods of silence from my side, you have always been there, and you deserve my deepest gratitude.

Roland Gårdhagen

Linköping, November 2013. 



\section{Funding}

The work was supported by grants from the Swedish Research Councill (Vetenskapsrådet):

- VR 2004-3803

- VR 2007-4085

- VR 2010-4282

Computational resources were provided by the Swedish National Infrastructure for Computing under the following grants. The calculations were performed at National Supercomputer Centre (NSC), Linköping, Sweden.

- SNIC 025/12-22

- SNIC 020/11-27

- SNIC 014/10-15

- SNIC 022/09-11 



\section{List of Papers}

This thesis is based on the following five papers, which will be referred to by their Roman numerals:

I. Feasibility of Patient Specific Aortic Blood Flow CFD Simulation, Johan Svensson, Roland Gårdhagen, Einar Heiberg, Tino Ebbers, Dan Loyd, Toste Länne, Matts Karlsson, Proceedings of MICCAI (Medical Image Computing and Computer-Assisted Intervention), Copenhagen, Denmark, ISBN 3540-44707-5, 2-4 October, 2006.

II. Large Eddy Simulation of Stenotic Flow for Wall Shear Stress Estimation - Validation and Application, Roland Gårdhagen, Jonas Lantz, Fredrik Carlsson, Matts Karlsson, WSEAS Transactions on Biology and Biomedicine, 2011, Vol. 8, 86-101.

III. Quantifiying Turbulent Wall Shear Stress in a Stenosed Pipe Using Large Eddy Simulation, Roland Gårdhagen, Jonas Lantz, Fredrik Carlsson, Matts Karlsson, Journal of Biomechanical Engineering, 2010, Vol. 132, 061002 .

IV. Quantifiying Turbulent Wall Shear Stress in a Subject Specific Human Aorta Using Large Eddy Simulation, Jonas Lantz, Roland Gårdhagen, Matts Karlsson, Medical Engineering and Physics,2011, Vol.34, 11391148 .

V. Large Eddy Simulation of Pulsating Flow Before and After CoA Repair - CFD for Intervention Planing, Roland Gårdhagen, Fredrik Carlsson, Matts Karlsson. Submitted for publication. 



\section{Nomenclature}

SI units are used for all dimensions.

\section{Upper Case Latin}

$B_{i j} \quad$ Normalized two-point correlation

C Constant

$C_{\mu} \quad$ Model constant

D Diameter of the unoccluded part of a pipe

$D \quad$ Diameter

E Spectral energy

$E^{*} \quad$ Normalized spectral energy

$I_{\text {in }} \quad$ Turbulence intensity at the inlet

$N \quad$ Number of samples

$N_{S} \quad$ Non-dimensional Strouhal number

$\mathrm{R} \quad$ Pipe raidus

Re Reynolds number

$U \quad$ Average velocity

$V \quad$ Volume

$T \quad$ i) Time over which the equations are averaged (RANS)

ii) Cycle time for phase averages, i.e. a cardiac cycle (pulsating flow)

WSS Wall shear stress vector 


\section{Lower Case Latin}

$d_{s t} \quad$ Diameter at the stenosis throat

$f \quad$ Frequency

$k \quad$ Turbulent kinetic energy per unit mass

$l \quad$ Length scale

$\bar{p} \quad$ Time average pressure

$\widetilde{p} \quad$ Filtered pressure

$p \quad$ Pressure

$\mathbf{r} \quad$ Distance between the points of a two-point correlation

$s_{i j} \quad$ Strain rate tensor

$\overline{s_{i j}} \quad$ Strain rate based on time averaged velocity

$\widetilde{s_{i j}} \quad$ Strain rate based on filtered velocity

$t \quad$ Time

$t_{i j} \quad$ Stress tensor

$u \quad$ Velocity

$\bar{u} \quad$ Time average velocity

$\widetilde{u} \quad$ Filtered velocity

$u_{i} \quad$ Velocity components in spatial directions $i=1,2,3$

$u_{i}^{\prime} \quad$ Fluctuating velocity components (RANS)

$u_{i}^{\prime \prime} \quad$ Fluctuating velocity components (LES)

$u_{\tau} \quad$ Friction velocity

$u_{s t} \quad$ Average velocity at the stenosis throat

$u^{+} \quad$ Non-dimensional velocity

$u_{i, r m s} \quad$ RMS value of the $i$ :th velocity component

$\overline{u_{i}^{\prime} u_{j}^{\prime}} \quad$ Specific Reynolds stress tensor

$\widehat{u_{i}^{\prime} u_{j}^{\prime}} \quad$ Specific sub grid scale stress tensor

$x, y, z$ Directions in a cartesian coordinate system

$x_{i} \quad$ Directions in a cartesian coordinate system, $i=1,2,3$

$\mathrm{x} \quad$ Point where a two-point correlation is calculated

$y^{+} \quad$ Non-dimensional wall distance 


\section{Greek}

$\Delta x \quad$ Cell size in the $x$-direction

$\Delta x^{+} \quad$ Non-dimensional cell size in the $x$-direction

$\Delta z \quad$ Cell size in the $z$-direction

$\Delta z^{+} \quad$ Non-dimensional cell size in the $z$-direction

$\epsilon \quad$ Dissipation rate

$\eta \quad$ Kolmogorov length scale

$\kappa \quad$ Wave number

$\mu \quad$ Dynamic viscosity

$\nu \quad$ Kinematic viscosity

$\nu_{S G S} \quad$ Sub grid scale viscosity

$\nu_{t} \quad$ Eddy viscosity

$\nu_{t_{k-\epsilon}} \quad$ Eddy viscosity in the $k-\epsilon$ model

$\phi \quad$ Arbitrary variable

$\rho \quad$ Density

$\omega \quad$ Specific dissipation rate

$\tau \quad$ Kolmogorov time scale

$\tau_{i j} \quad$ Sub grid stresses

$v \quad$ Kolmogorov velocity scale 



\section{Abbreviations}

$\begin{array}{ll}\text { ax } & \text { Axial } \\ \text { circ } & \text { Circumferential } \\ \text { CFD } & \text { Computational Fluid Dynamics } \\ \text { CFL } & \text { Courant Friedrichs Levy } \\ \text { CoA } & \text { Coarctation of the Aorta } \\ \text { CT } & \text { Computer Tomography } \\ \text { DES } & \text { Detached Eddy Simulation } \\ \text { DNS } & \text { Direct Numerical Simulation } \\ \text { EC } & \text { Endothelial Cell } \\ \text { HP } & \text { Hagen-Poiseuille } \\ \text { LDL } & \text { Low-Density Lipoprotein } \\ \text { LES } & \text { Large Eddy Simulation } \\ \text { LDV } & \text { Laser Doppler Velocimetry } \\ \text { MC } & \text { Million Cells } \\ \text { MRI } & \text { Magnetic Resonance Imaging } \\ \text { OSI } & \text { Oscillatory Shear Index } \\ \text { PANS } & \text { Partially Averaged Navier-Stokes } \\ \text { PAWSS } & \text { Phase Averaged Wall Shear Stress } \\ \text { RANS } & \text { Reynolds-Averaged Navier-Stokes } \\ \text { RNG } & \text { Renormalization Group } \\ \text { RMS } & \text { Root Mean Square } \\ \text { SAS } & \text { Scale Adaptive Simulation } \\ \text { SGS } & \text { Sub Grid Scale } \\ \text { SRS } & \text { Scale Resolving Simulation } \\ \text { SST } & \text { Shear Stress Transport } \\ \text { TKE } & \text { Turbulent Kinetic Energy } \\ \text { TAWSS } & \text { Time Averaged Wall Shear Stress } \\ \text { tSST } & \text { Transitional Shear Stress Transport } \\ \text { URANS } & \text { Unsteady Reynolds-Averaged Navier-Stokes } \\ \text { WSS } & \text { Wall shear stress } \\ & \end{array}$





\section{Contents}

$\begin{array}{ll}\text { Abstract } & \text { iii }\end{array}$

$\begin{array}{lr}\text { Populärvetenskaplig beskrivning } & \mathbf{v}\end{array}$

Acknowledgments vii

Funding $\quad$ ix

List of Papers $\quad x i$

Nomenclature $\quad$ xiii

$\begin{array}{ll}\text { Abbreviations } & \text { xvii }\end{array}$

$\begin{array}{ll}\text { Contents } & \text { xix }\end{array}$

1 Introduction $\quad 1$

1.1 Background . . . . . . . . . . . . . . . . . . 1

1.2 Cardiovascular Flow and Diseases . . . . . . . . . . 1

1.2.1 Atherosclerosis . . . . . . . . . . . . 3

1.2.2 Thrombus Formation ............. 5

1.3 Turbulent Flow . . . . . . . . . . . . . 5

1.3.1 Turbulent Structures and Spectral Energy Distribution . . 9

1.4 Analysis of Cardiovascular Flow . . . . . . . . . . . . . . . 12

1.4.1 Magnetic Resonance Imaging . . . . . . . . . . . . . 12

1.4.2 Numerical Simulation: Computational Fluid Dynamics . . 12

1.5 Progress within Related Research Fields . . . . . . . . . . . . . . 13

1.6 Aim . . . . . . . . . . . . . . . . . . . 14

1.7 Limitations . . . . . . . . . . . . . . . . . . . . . 14

xix 
2 Method 15

2.1 CFD - the Basics . . . . . . . . . . . . . . . 15

2.1.1 The Finite Volume Method . . . . . . . . . . . . . . 17

2.2 Simulation of Turbulent Flow . . . . . . . . . . . . . . . 17

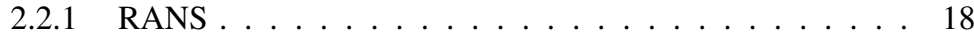

2.2 .2 LES . . . . . . . . . . . . . . . 21

2.2 .3 Mixed Models . . . . . . . . . . . . . . . . 22

2.2.4 Resolution and Quality Assessment of LES - General Considerations .................. 23

2.2.5 Resolution of LES in Constricted Pipe with Dilatation -

Present Work . . . . . . . . . . . . . . 25

2.3 Numerical Settings and Boundary Conditions . . . . . . . . . . 27

2.4 WSS Post-Processing . . . . . . . . . . . . . . 28

3 Results and Discussion $\quad 31$

3.1 Biofluid Simulation . . . . . . . . . . . . . . . . 31

3.2 CFD Simulation of Transitional Arterial Flow . . . . . . . . . . 32

3.2.1 Time Averaged and Fluctuating Velocity . . . . . . . . . . 32

3.2 .2 Energy Spectra . . . . . . . . . . . . . . . . 33

3.2 .3 RANS Modeling . . . . . . . . . . . . . . . 35

3.3 WSS in Turbulent Flow . . . . . . . . . . . . . . . 37

3.3.1 Steady Flow in an Axisymmetric Constricted Pipe . . . . 37

3.3.2 WSS in Pulsating Flow . . . . . . . . . . . . . . . 40

3.4 Towards Intervention Planning . . . . . . . . . . . . . . 41

3.5 Outlook ......................... 45

4 Review of Appended Papers $\quad 47$

Paper II . . . . . . . . . . . . . . . . . . . . . . 71 


\section{Chapter 1}

\section{Introduction}

\subsection{Background}

Biofluid dynamics is, as the name says, when fluid dynamics is applied for biological problems. From a research perspective this is an opportunity to combine state-of-the-art technology from two completely different disciplines to extend the borders even further.

Techniques like magnetic resonance imaging (MRI) and computer tomography (CT) today offer amazing possibilities to assess the actual state of a body. Injuries and diseases deep inside the tissue can be detected easier than ever before. However, this kind of images show the present, not predictions of the future.

Within fluid dynamics, detailed and advanced simulations of fluids in motion are now routine thanks to the development of computer technology that has enabled large and demanding calculations to an extent that was impossible even just a decade ago. Now, with a patient specific vessel model based on anatomical and physiological data from e.g. MRI, flow simulations can be conducted in a relatively automatized way.

Next step is to modify the vessel model in order to evaluate optional treatments in order to find an optimal patient specific solution. A remaining fluid dynamics challenge is also to accurately, and to an affordable price, simulate turbulent flow, and subsequently quantify its effects on the cardiovascular function.

\subsection{Cardiovascular Flow and Diseases}

All parts of the body require a continuous supply of nutrients and oxygen along with removal of waste products for proper function and survival. This is provided by the cardiovascular system, principally consisting of the heart, blood vessels, and blood $[1,2]$. The heart, or more precisely its left side, pumps blood into the 
aorta, the major artery of the body (with a diameter of 2-3 cm [2] (p. 692)), going from the upper part of the chest down to the lower part of the abdomen, where it ends with the bifurcation and iliac arteries. Arterial branches from the aorta distribute the blood to various parts of the body, e.g. the subclavian arteries supplying the arms, the carotid arteries supplying the head, renal arteries supplying the kidneys etc, and yet smaller branches distribute the blood out to the capillary net in the tissue, where the exchange of oxygen and waste products takes place. Even the heart itself needs a continues supply of blood, which is obtained through the coronary arteries.

Deoxygenated blood in the tissues goes back through the venous system into larger and larger vessels until vena cavas end in the right heart for further distribution to the lungs, oxygenization, and subsequent return to the left heart and a new journey out in the body. Under normal resting conditions the heart pumps about 5 liters of blood per minute through the body [2] (p. 636). From birth to death this process continues - uninterruptedly. Under normal conditions blood flow is often considered to be laminar, possibly with the existence of secondary flows [3], but sometimes turbulence like disturbances are recognized even in the healthy arterial flow [4] (Ch. 3).

Due to its crucial role, any disturbances of the cardiovascular function might be fatal. Blockage of a blood vessel and interrupted blood supply may lead to ischemia (insufficient supply of blood in relation to the need of the tissue) and infarction (death of tissue due to interrupted blood supply). The most vulnerable cites are the heart (myocardial infraction) and brain (cerebral infarction or stroke) $[2,5]$. Thus, one of the most serious threats for a life resides within the body itself, and in the year 2008 cardiovascular disease was listed as the underlying cause of $33 \%$ of all deaths, and related to $55 \%$ of the deaths in the United States [6].

Occlusion of a blood vessel may either occur instantaneously or can progress gradually during several years, even decades [5]. The long-time scenario involves changes in and growth of the vessel wall and is known as atherosclerosis. The sudden blockage occurs when a particle, for some reason, enters the cardiovascular system and reaches a vessel smaller than itself directly or after traveling with the blood. Such a particle can e.g. be a clot formed by the constituents of the blood itself, a thrombus. Risk factors for both of these events are central within this work and therefore the following sections give some information about why and how these diseases occur. 


\subsubsection{Atherosclerosis}

Arterial walls consist of three layers: the innermost intima, the outermost adventitia, and between these the media. Atherosclerosis is a growth of the intima and possibly media layers leading to a gradual occlusion of lumen as a result of a series of events inside the vessel wall. The pathogenesis is described extensively in e.g. [7-10], and can roughly be summarized as follows.

Low-density lipoprotein (LDL) and monocytes migrate from the blood through the endothelium and accumulate within the intima where they meet smooth muscle cells from the media. This results in so called fatty streaks which are the very first changes in the vessel wall towards development of atherosclerotic plaques. These are common even in children. Within some fatty streaks, the pathologic process continues and next step in the disease progression is proliferation and differentiation of monocytes into macrophages, and subsequent uptake of oxidated LDL particles resulting in formation of foam cells, which when they die form a mass of lipids that with time can develop into a fibrous atherosclerotic plaque consisting of a necrotic core covered by a fibrous cap towards lumen.

Atherosclerotic plaques can be divided into, at least, two categories: vulnerable plaques that are likely to rupture, and stable plaques that are unlikely to rupture [11]. The former typically have a thinner fibrous cap [10]. As the disease progresses, a larger and larger part of lumen becomes occluded. However, lesions blocking an entire vessel are not the most probable threat; rather this is rupture of the fibrous cap and accompanying formation of blood clots or thrombi [10] (see Sec. 1.2.2) causing sudden blockage of the blood vessel.

It should again be emphasized that development of an atherosclerotic plaque is a complex series of events and circumstances, and that the presented description merely illustrates a few major identifiable events and states of the disease progression.

\section{Endothelial Cells and Wall Shear Stress}

As the bounding surface between the wall and the blood, the layer of endothelial cells (EC) is believed to have a central role in the genesis of atherosclerosis. It is directly exposed to the flowing blood and thereby affected by the frictional load due to the motion, which is referred to as the wall shear stress (WSS), see Fig. 1. Mathematically WSS is obtained as the viscosity (of blood), $\mu$, multiplied by the velocity gradient (shear rate) in the wall normal direction, as expressed by Eq. 1 .

$$
\mathrm{WSS}=\mu \frac{\partial u}{\partial y}
$$




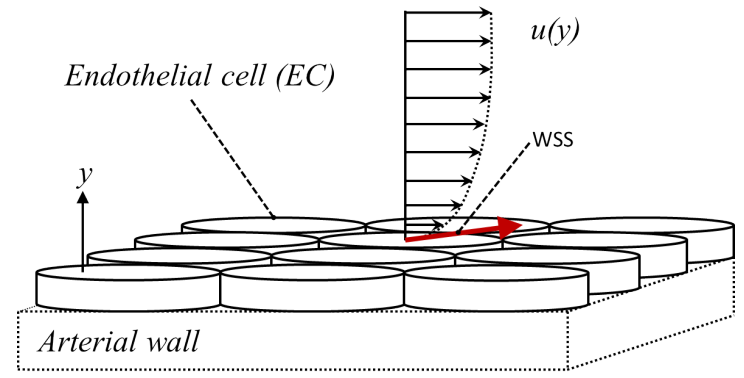

Figure 1: The velocity gradient (shear rate) in the normal direction away from the wall causes a frictional load, the wall shear stress (WSS), on the arterial wall. WSS is computed as blood viscosity times shear rate. It affects the layer of endothelial cells that covers the wall and has a central function in the cardiovascular system.

Thus, accurate prediction of WSS generally requires accurate estimations of the velocity gradients at the wall. However, in the theoretical case of steady, fully developed laminar flow of an incompressible (constant density) fluid in a (long ${ }^{1}$ ) straight circular pipe, Eq. 1 reduces to

$$
\mathrm{WSS}_{H P}=\frac{8 \mu U}{D}
$$

where $\mu$ is the dynamic viscosity, $U$ the cross-sectional average velocity, and $D$ the pipe diameter. This type of flow is known as Hagen-Poiseuille flow [4, 13], and might show an insidious resemblance to blood flow in arteries. The complexity of which in general though makes this highly simplified approach insufficient [14]. E.g. as curvature, tapering, and branches prevent the flow from reaching the required fully developed state. Hence, the velocity gradient in Eq. 1 must be obtained in some other way.

The role of hemodynamics in general and WSS in particular in development of atherosclerosis has been studied extensively during the last 40 years [11, 15-22], because independent of other known risk factors atherosclerotic plaques tend to form on the inner part of curved arteries and near branches or bifurcations [5, 11]. Both experimental and numerical studies have been conducted, and have resulted in identification of regions with low and/or oscillating WSS as particularly prone to development of atherosclerosis [11, 23-29]. Still, though, it seems that the precise role of EC in disease initiation and progression is not fully clarified. There are, however, several ways in which EC sense stress and subsequently react [18].

\footnotetext{
${ }^{1}$ In laminar flow the entry length (to obtained fully developed flow) is $0.06 \mathrm{Re}_{D}$ [12], (p. 240).
} 


\subsubsection{Thrombus Formation}

As a response to injuries of the vessel wall a chain of reactions and events start to repair the damage [2]. This includes a relatively quick formation of blood clots to temporally seal the leakage. The fibrous cap of an atherosclerotic plaque might as mentioned rupture, in which case substances initiating the healing of a damaged vessel are exposed and activated. This can result in a quick formation of a thrombus (blood clot), that effectively blocks the vessel (thromboembolism), or possibly travels downstream with the blood and blocks a smaller vessel.

Influence of hemodynamics on thrombus formation has gained increased attention, and studies have e.g. found that shear rates above certain threshold values seem to promote thrombus formation $[30,31]$, and that various features of turbulent flow also might influence [32]. Turbulent flow has also been suggested to have additional degenerative effects on blood, which is commented more in the appended papers. This topic is still relatively unexplored.

\subsection{Turbulent Flow}

Fluid flows are often classified or characterized in different ways e.g. viscous or inviscid, compressible or incompressible, steady or unsteady, laminar or turbulent etc. This tells us about physical phenomenon that significantly will affect the motion of fluid, and thereby it also indicates a required level of model-complexity if the flow is to be simulated.

There is a difference between the first two and the last two of the above mentioned classifications in that all flows strictly are viscous as well as compressible, but these effects can be vanishingly small, and may then be neglected with significantly simplified calculations as the benefit. For blood flow the density variations are very small (i.e. incompressibility is a very reasonable assumption), whereas viscous effects (like WSS) are crucial. Steady and unsteady as well as laminar and turbulent, on the other hand, are real and possible states, with completely different character. Blood flow is unsteady due to the pulsation, and the Reynolds number ${ }^{2}$, Eq. 3, is within the transitional regime [4] (Table 3.1). For industrial applications most flows are turbulent and thereby also unsteady, as turbulent flows are inherently unsteady.

$$
\operatorname{Re}=\frac{\rho U D}{\mu}
$$

\footnotetext{
${ }^{2}$ The Reynolds number is based on a characteristic length for the particular flow. For pipe flow this is the diameter, $D$. For clarity the characteristic length can be indicated as an index, i.e. $\operatorname{Re}_{D}$, however since only pipe flows are considered within this work Re will, unless otherwise noticed, be assumed to be based on the pipe diameter.
} 
As an illustrative example, consider the flow through the constricted pipe in Fig. 2 (which has been used for a large part of this work). It can be thought of as a generalized model of a stenotic blood vessel. Steady, fully developed laminar flow enters the pipe to the left at a Reynolds number of 2000 , based on unoccluded diameter (D) and cross-sectional average velocity.

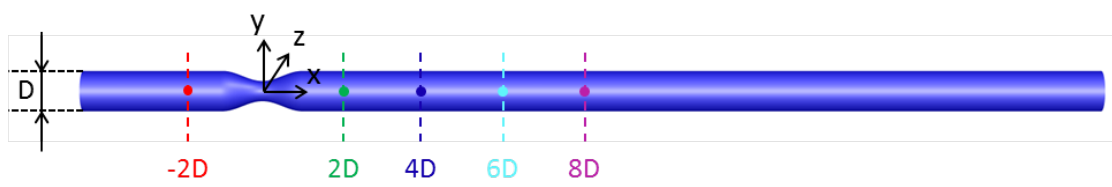

Figure 2: Stenosed pipe used for investigation and simulation of turbulent flow in the arterial system. The axial position is indicated in unoccluded diameters (D) downstream or upstream of the stenosis throat, where the coordinate system is located in this figure.

Instantaneous contour plots of normalized $x$-, $y$ - and, $z$-components of the velocity in the $x y$-plane at two instants of time are shown in Fig. 3 (a), (b), and (c) respectively, and monitors of the same components at the centerline points in Fig. 2 are shown in Fig. 4. Upstream of the stenosis (-2D) the velocity remains (boringly) constant throughout time, as prescribed by the inlet boundary condition, whereas a jet breaks up and creates highly unsteady flow in the post-stenotic region. This is associated with transition from laminar to turbulent flow. The monitor plots show a clear development of the turbulence. From onset around $2 \mathrm{D}$ to very intense oscillations around $4 \mathrm{D}$, with seemingly random fluctuations in time, after which the oscillations decrease and the signals get smoother, indicating relaminarization.

Key features to notice are the difference between laminar and turbulent flows, and that turbulence can be more or less strong, even change and develop with the flow. There is also an inherent three-dimensionality although there is no net flow in the non-axial directions; instantaneously these velocity components are finite and with a similar, randomized oscillatory behavior as the axial component. 


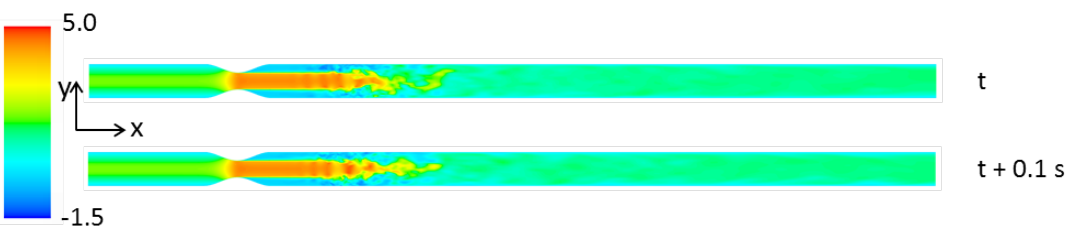

(a)

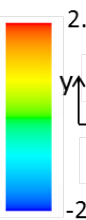

2.0

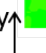

$\longrightarrow$

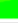

$-2.0$

(b)

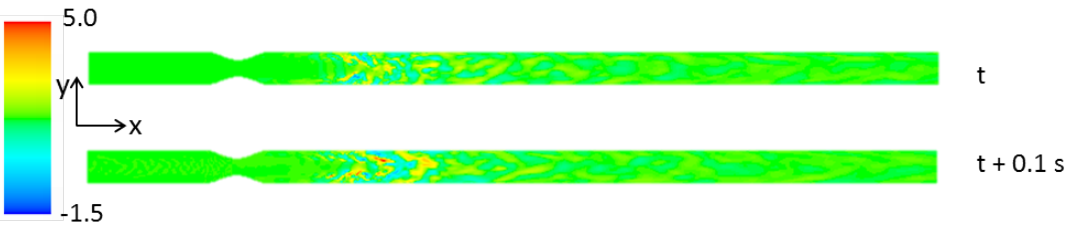

(c)

Figure 3: Instantaneous contour plots of the velocity components in the $x y$-plane. (a) $x$-component, (b) $y$-component, (c) $z$-component. The images were captured at two instants of time separated by $0.1 \mathrm{~s}$. The velocity is normalized with the cross sectional average velocity, $U$, at the inlet. Steady, fully developed laminar flow enters the pipe in the $x$-direction and a jet develops after the constriction. Its break down is associated with transition to turbulent flow. The three-dimensionality appears clearly from random oscillations of the $y$ - and $z$-components despite no net flow in this direction. Over time the flow is symmetric in the $x y$-and $y z$-planes. 


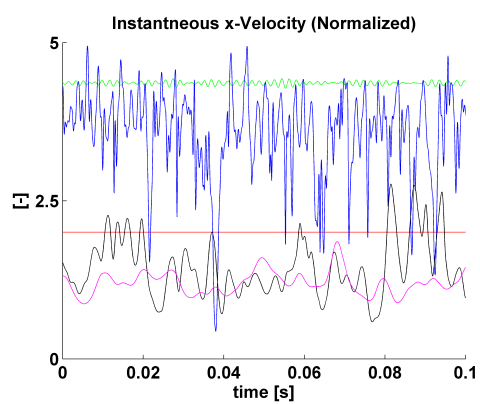

(a)

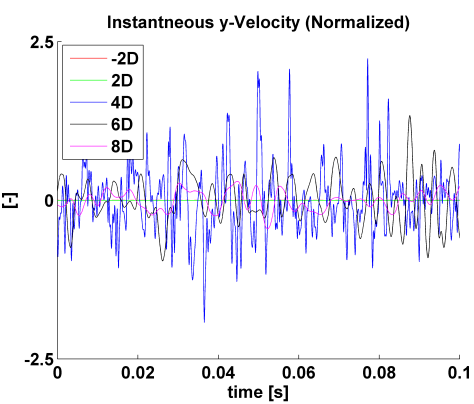

(b)

Figure 4: Velocity monitored at the centerline points in Fig. 2. $x$-component (axial) (a) and $y$-component (b). No oscillations, i.e. laminar flow, upstream of the stenosis, while smaller or larger oscillations of different frequencies - typical manifestations of turbulence - characterize the post-stenotic flow. Axially the oscillations are superimposed onto a finite time averaged value due to the net flow in this direction, in contrast to the $y$ component that oscillates around zero.

A formal definition of turbulence has not been established, but some characteristic features are often mentioned, see e.g. [33] (Ch. 1), and can at least partly be discerned in the figures.

- Turbulent flows are associated with relatively high Reynolds numbers ${ }^{3}$

- Turbulent flows are always and inherently three-dimensional. In the pipe the main flow is in the axial direction, but the other components are instantaneously non-zero.

- The flow field is unsteady and the properties show seemingly randomized and irregular oscillations in space and time.

- The energy is transfered through an energy cascade from large to small turbulent structures.

- Through dissipation kinetic energy is continuously converted to internal energy.

\footnotetext{
${ }^{3}$ When, in terms of Reynolds number, transition occurs depends on several factors, including the shape of the object. For flow in pipes and flow a long flat plates laminar flow can be expected if $\operatorname{Re}_{D}<2000$ and $\operatorname{Re}_{x}<1000$ 000, respectively, [13] (p. 12 and 218). $\operatorname{Re}_{D}$ and $\operatorname{Re}_{x}$ are here the Reynolds numbers based on pipe diameter, $D$, and distance $x$ from the leading edge of the plate.
} 
The second last item was commendably summarized by Lewis Fry Richardson already in 1922 [34] (p. 66):

\author{
"big whirls have little whirls \\ that feed on their velocity, \\ and little whirls have lesser whirls \\ and so on to viscosity - \\ in a molecular sense"
}

\title{
1.3.1 Turbulent Structures and Spectral Energy Distribution
}

The oscillatory velocity signals reflect regions of different sizes with different velocity passing the monitor point. Such a region is referred to as an eddy or turbulent structure and is simply thought of as a spatial region in which the motion is "at least moderately coherent" [35] (p. 183). The size of the region and its representative velocity are, in turn, referred to as its length scale and velocity scale, respectively. Fig. 5 shows larger turbulent structures in the stenotic pipe as illustrated by the Q-criterion, which identifies regions of the flow where rotation dominates strain $[36,37]$.

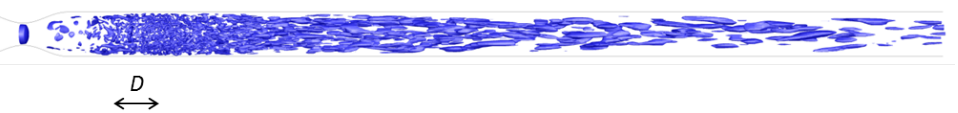

Figure 5: Turbulent structures - eddies - of various sizes and shapes illustrated by the Q-criterion. Smaller and less anisotropic structures appear close to the stenosis whereas larger prolonged structures develop in the less turbulent flow further downstream, in accordance with the monitors in Fig. 4.

Closer analysis reveals a range of scales (and thus structures) from those with dimensions comparable to bulk flow and geometry, to very small ones where viscous forces and inertial forces balance each other, and the Reynolds number based on length and velocity scales of these eddies therefore is around unity. These very smallest scales are known as Kolmogorov scales, and can be estimated according to Eq. 4 (length scale), Eq. 5 (time scale), and Eq. 6 (velocity scale)

$$
\begin{gathered}
\eta=\left(\nu^{3} / \epsilon\right)^{1 / 4} \\
\tau=(\nu / \epsilon)^{1 / 2} \\
v=(\nu \epsilon)^{1 / 4}
\end{gathered}
$$


where $\nu$ is the kinematic viscosity and $\epsilon$ the turbulent dissipation [38]. The Kolmogorov scales decrease as the mean flow Reynolds number increases [35] (p. 182).

Eddies of all sizes possess a certain amount of turbulent kinetic energy (TKE), and it appears that most of this resides in the larger eddies. These interact with the mean flow, and thereby extract the energy from this. Larger eddies are then deformed, stretched, and destructed into smaller eddies, which in turn undergo the same procedure resulting in a transfer of energy from the mean flow through eddies of decreasing sizes down to the Kolmogorov scales, where dissipation (due to friction) finally converts the kinetic energy to thermal energy, which increases the temperature (for blood flow this temperature increase is negligibly small though). This process is known as the energy cascade [35] (p. 183).

Fig. 6 illustrates schematically the variation of energy content with wave number, $\kappa$, which is inversely proportional to the eddy size $l$ according to $\kappa=\frac{2 \pi}{l}$ [35] (p. 188). The abscissa could also have shown frequency associated with the eddies, as this varies similarly to the wave number.

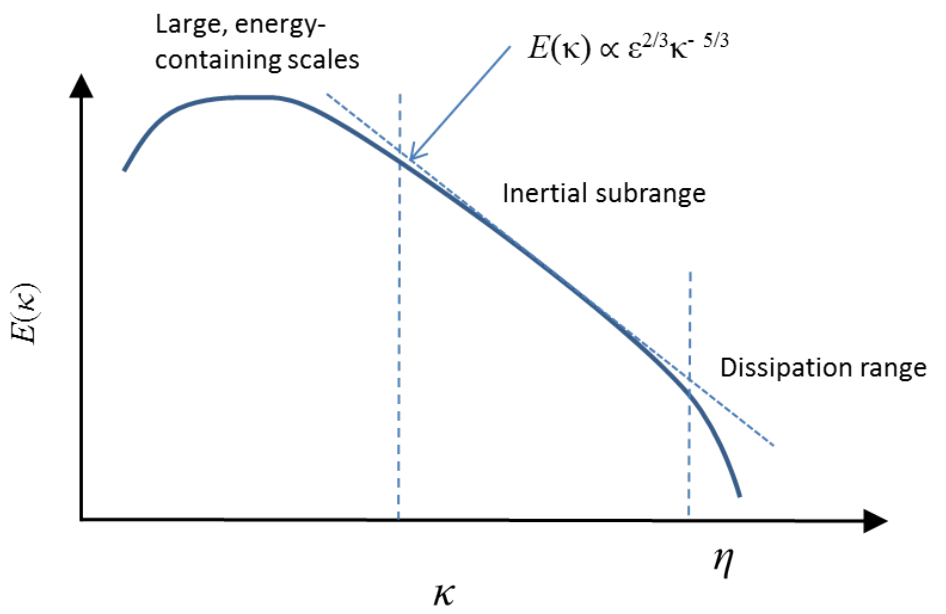

Figure 6: Schematic illustration of the turbulent energy $E$ associated with different wave numbers $\kappa$ (or eddy sizes). Most energy resides in the larger eddies. In the intermediate range of wave numbers, the inertial subrange, for which the $-5 / 3$ relation (Eq. 7) applies, is found. Finally the smallest, dissipative scales (Kolmogorov scales), corresponding to the highest wave numbers, only contain a minor fraction of the energy. 
The turbulent kinetic energy associated with the velocity fluctuations is defined in Sec. 2.2.1. Fig. 7 shows this for the pipe flow along the centerline (extracted from LES). In accordance with previous plots, most energy is found shortly after the stenosis in a rather narrow region, after which the turbulence decays downstream.

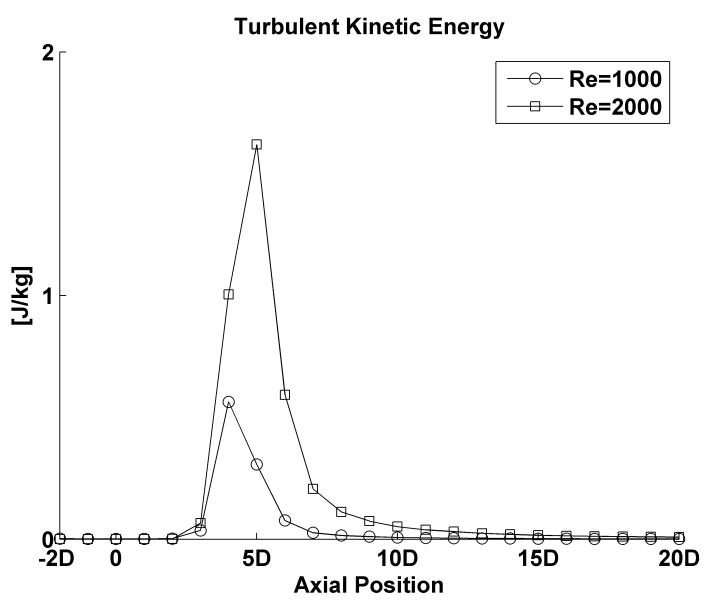

Figure 7: Turbulent kinetic energy per unit mass, $k$, along the pipe in Fig. 2 for $\operatorname{Re}=2000$ (extracted from LES, see Sec. 2.2). Transition to turbulence occurs after the stenosis (0D) and consequently there is a sudden increase in $k$ associated with this. As indicated by Fig. 3 to 5 the turbulence decreases downstream, which is manifested by decreasing $k$.

As the larger eddies interact with the mean flow, these tend to be rather anisotropic, whereas the smaller eddies for sufficiently high Reynolds numbers tend to approach a statistically isotropic state, which is independent of the larger scales and seemingly universal for all turbulent flows. This is known as Kolmogorov's hypothesis of local isotropy and the range of scales where isotropy exists is known as the universal equilibrium range.

Furthermore Kolmogorov argued that the statistics of the larger scales in the equilibrium range is uniquely determined of the dissipation, $\epsilon$ (independent of the viscosity). This is known as Kolmogorov's second similarity hypothesis. Dimensional analysis then yields the well-known relation between energy content, dissipation, and wave number in this range [35] (p. 189) or [39] (p. 42).

$$
E(\kappa)=C \epsilon^{2 / 3} \kappa^{-5 / 3}
$$

where $C$ is a constant and $\kappa$ the wave number. 
Finally, concerning turbulence, pipe flow (e.g. blood flow) as discussed above is just one example. For sufficiently high Reynolds numbers (different for different flow situations), all types of flows will become turbulent.

\subsection{Analysis of Cardiovascular Flow}

As discussed in Sec. 1.1 MRI is invaluable for assessing the actual state of the body, whereas simulations offer a unique predictive functionality. This section provides a short introduction to each modality.

\subsubsection{Magnetic Resonance Imaging}

Magnetic resonance imaging (MRI) provides amazing possibilities for anatomical investigations as well as flow assessment, the latter is routinely used for threedimensional time resolved velocity measurements in the heart itself and in the blood vessels. Recently the technique has also been used to quantify turbulent blood flow by measuring the turbulent kinetic energy [40, 41] and comparison with CFD simulations shows good agreement [42]. Since turbulent disturbances rarely occur in a healthy cardiovascular system [4] (Ch. 3), TKE might be an informative parameter when diagnoses are being made. Due to the limited resolution though, WSS estimated directly using MRI data has not been a successful option [43].

\subsubsection{Numerical Simulation: Computational Fluid Dynamics}

By constructing a computer model of a vessel and applying a numerical technique referred to as computational fluid dynamics (CFD), flows, e.g. in a blood vessel, can be simulated to yield the same quantities as obtained from measurements. CFD is since decades used extensively for technical applications, e.g. to simulate and evaluate the flow around different vehicles (aircraft, cars, trains etc.) in order to find the configuration with optimal performance in some sense. These cases are examples of external flow. Internally, CFD can be used to simulate flows in pipes, mixing chambers, heat exchangers, combustors, etc. for various reasons. Thus, the general technique for flow simulations is far from novel, and several calculation methods have been developed. Also, a number of different softwares are available. These span from highly specialized and accurate research codes, "special-purpose codes", used exclusively within the academia, to "general-purpose codes", which are intended to work reasonably for a wide range of applications. Both types have their advantages and disadvantages. 
In short, the procedure involves creation of a computer model of the geometry in which the flow is to be studied, specification of boundary conditions representing the interaction between the flow in the computational domain and the surroundings, solving some equations for velocity, pressure, density, and perhaps temperature with high resolution inside the domain, and evaluation of the results. Described like this, the procedure sounds seductively simple, but there are several potential pitfalls. To get reliable results requires knowledge and experience for each step: where to put the boundaries, which are the proper boundary conditions, what about the numerical details, etc. The modeling is a crucial part of the procedure, and therefore the problem is usually not just to get some results, but the question is can you trust the results you have?

\subsection{Progress within Related Research Fields}

For a detailed description of related previous works the reader is referred to the appended papers, this section gives an overview of how this thesis generally is related to different disciplines and the research progress within these.

As the topic of biofluid mechanics is highly interdisciplinary, relevant works can be sorted into one or more of the categories: computational fluid dynamics, experimental fluid dynamics, and medical investigations and comparisons. Computational studies of increasing complexity are continuously being published as the development of numerical modeling progresses and more computational power becomes available.

Roughly speaking, when this work started simulations of turbulent blood flow occasionally appeared among a majority of laminar models, but since then DNS (described in Sec. 2.2) of steady as well as pulsating stenotic flows in idealized as well as more realistic geometries has been conducted [44-46]. Also, some DNS studies of channel flow have been valuable for comparison and quality assessment during the present work [47, 48]. RANS models (see Sec. 2.2.1) have been explored for turbulent and transitional biofluid problems, but so far with moderate success [49-51]. Instead scale resolving simulation (SRS), particularly LES [52, 53] (described in Sec. 2.2), has been applied with promising results. Also worth to mention, although not included in this work, is the possibility to model fluid-structure interaction [54].

Within the experimental field a series of Laser Doppler velocimetry (LDV) measurements of transitional pipe flow were conducted during the late 1970's and early 1980's [55-58], and has since then been used for comparison of numerical models. Few similar related measurements have been reported. MRI has, thanks to its wide use at hospitals, contributed to the progress of cardiovascular modeling in different ways: as a source of input parameters to simulation models, for 
better understanding of cardiovascular flow, and for comparison with simulation results [59]. Particularly interesting is the growing interest to measure and quantify turbulence parameters using MRI [40-42, 60].

Until quite recently focus was essentially on investigation of hemodynamics and establishment of correlations between hemodynamics and cardiovascular disease. Quite naturally, with that foundation laid, next step seems to be the application of acquired knowledge for predictive use, i.e. clinical implementation. Here, CFD simulations offer a unique possibility to evaluate alternative treatments on a patient specific level [61-64] in advance, which is also an underlying theme for this thesis.

\subsection{Aim}

The aim of the work was to demonstrate the feasibility of CFD as a predictive tool to use for intervention planning of cardiovascular diseases. This included use of LES for accurate modeling of turbulent cardiovascular flow, and possibility to evaluate several different treatments. Quantification of WSS, as well as other informative hemodynamic parameters, was central, due to the importance of comparable measures for the predictive use.

\subsection{Limitations}

It was decided to confine this work to incompressible flow of a Newtonian fluid in models with rigid walls. 


\section{Chapter 2}

\section{Method}

\subsection{CFD - the Basics}

Motion of fluids is described by three fundamental physical principles:
i Mass is conserved
ii Newton's second law
iii Energy is conserved

Conserved in the above formulations should be interpreted as "neither created nor destroyed". Expressed in mathematical terms these statements constitute the foundation of CFD in terms of a set of governing equations known as the continuity equation (from i), the momentum equations (from ii), and the energy equation (from iii). As discussed previously, the level of complexity of the model can vary, and with that the complexity of the formulation of the governing equations. Assuming incompressible flow, which is reasonable for blood flow, and a Newtonian fluid, which is reasonable at least for blood flow in greater vessels [3], yield the following appearance of the continuity equation, Eq. 8, and the momentum equations, Eq. 9 [38] (p. 35) or [13] (Ch. 2.3 - 2.4) (in a Cartesian coordinate system, and using tensor notation, which will also be utilized in the forthcoming).

$$
\begin{aligned}
\frac{\partial u_{i}}{\partial x_{i}} & =0 \\
\rho \frac{\partial u_{i}}{\partial t}+\rho u_{j} \frac{\partial u_{i}}{\partial x_{j}} & =-\frac{\partial p}{\partial x_{i}}+\frac{\partial t_{j i}}{\partial x_{j}}
\end{aligned}
$$


where

$$
t_{i j}=2 \mu s_{i j}
$$

and

$$
s_{i j}=\frac{1}{2}\left(\frac{\partial u_{i}}{\partial x_{j}}+\frac{\partial u_{j}}{\partial x_{i}}\right)
$$

The variables in the equations are the density $\rho$, velocity components $u_{i}$, pressure $p$, viscosity $\mu$ (which is assumed to be constant), time $t$, and coordinate directions $x_{i}$, with $i=1,2,3$ in the Cartesian coordinate system. Einstein summation convention is employed. Since three-dimensional flow is considered, Eq. 9 is actually three equations, one for each spatial direction. The energy equation is only required if the temperature variation is large and heat transfer is of significance. In this study this is not the case, and hence the energy equation is not considered further.

CFD as a discipline has developed because no general analytical solution to Eq. 8 and Eq. 9 has been found, and hence the solution has to be numerical. A flow simulation requires a computational domain, that is a bounded region in space in which the flow is to be simulated. The boundary of this domain represents the interaction between the computational domain and the surrounding, and determines thereby to a great extent the flow within the domain. Essentially, the solver software is given information about the flow on the boundary and asked to compute the flow within it. Consequently, if the boundary conditions are inadequate so will the solution be.

The computational domain is divided into a (large or maybe even enormous) number of small cells, which constitute the computational mesh or grid. Discretized versions of the governing equations, i.e. algebraic approximations of the partial differential equations (Eq. 8 and Eq. 9), are then solved numerically in each cell, yielding the flow field in terms of velocity and pressure (and when needed density and temperature). If the flow is steady (time independent) there is clearly just "one flow field", whereas if the flow is unsteady the flow field will change from time to time, and hence the solution must be computed repeatedly in time to yield the temporally varying flow field. Roughly speaking, the resolution of the solution is determined by the size of the mesh and the size of the time step.

Some different numerical techniques are available, the most common today would be the finite volume method, at least for commercial use, whereas solvers for academic use and research are also based on finite difference methods, finite element methods, spectral methods, or spectral element methods. In this work the finite volume method has been applied, and is briefly described in next session. 


\subsubsection{The Finite Volume Method}

The idea with the finite volume method is to integrate the governing equations, Eq. 8 and Eq. 9, over each mesh cell (in this case a control volume), and to approximate the terms of the equations with algebraic expressions. For incompressible flow in three dimensions, the number of unknowns (three velocity components plus the pressure) equals the number of equations (continuity equation plus three momentum equations). Applied to every internal cell of the mesh (cells on the boundaries are managed by the boundary conditions), this yields a system of algebraic equations that can be solved for the unknown variables in each cell. Since the finite volume method implies integration over each cell the values of the variables will be spatial averages for each cell.

Concerning the discretization, there are several available options for both temporal and spatial terms. A thorough discussion of all these is beyond the scope of this book; the settings applied during this work are presented in Sec. 2.3.

\subsection{Simulation of Turbulent Flow}

Laminar flows, characterized by smooth variation of the flow field variables and moderate gradients, are typically easily sufficiently resolved in both space and time. However, the unsteadiness, the three-dimensionality, and the vast range of scales, particularly the small ones, in a turbulent flow quickly make the meshes unaffordably large as the Reynolds number increases. A simulation that does resolve all motion is called direct numerical simulation (DNS). This is extremely demanding in terms of computational power and is therefore only an option for moderate Reynolds numbers and simple geometries. Hence, there is an obvious need for a method that takes care of the turbulence to a minimal increase of computational cost. This section describes the most common available options for simulation of turbulent flows today. Some of the terminology has been presented in Sec. 1.3.

Fig. 8 provides a hierarchical overview of available options. The first choice is whether the turbulence is to be resolved (DNS) or modeled, but in reality, as discussed above, this decision rather concerns whether all or just a part of the turbulence is to be modeled. Reynolds-Averaged Navier-Stokes (RANS) equations are used to model all turbulent motion, whereas all other approaches include some amount of resolved turbulent motion. 


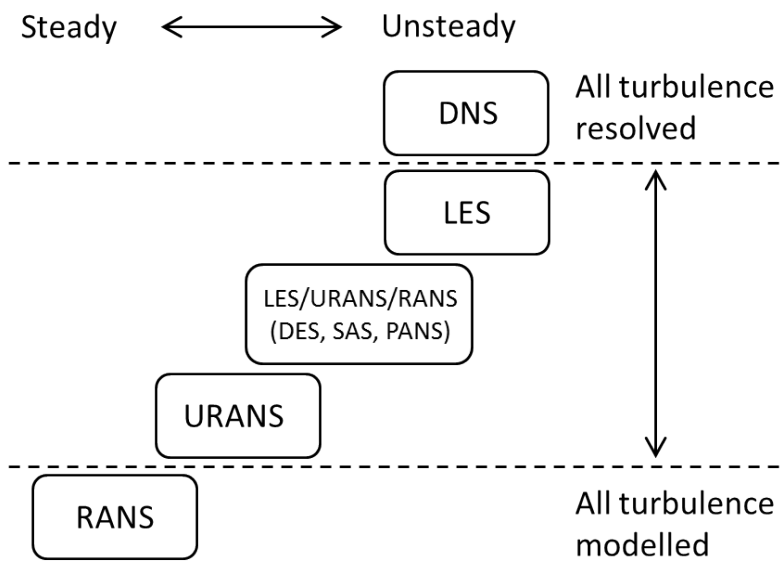

Figure 8: Hierarchical overview of available options for numerical simulation of turbulent flows. DNS resolves all spatial and temporal scales and is the most computational expensive. In RANS the effect of all turbulence on the mean flow is modeled, i.e. a steady solution is obtained, and RANS is therefore the computationally cheapest alternative. URANS is RANS with some unsteadiness allowed to develop. LES resolves larger eddies, and usually models the effects of the smaller once. Somewhere inbetween there is also a number mixed models, which operate in resolving mode or unresolving mode in different parts of the computational domain. These models are supposed to go unsteady when the unsteadiness of the flow is high, but remain steady in more quiescent regions, which is accomplished with different sensors for unsteadiness.

\subsubsection{RANS}

Complete modeling of all turbulent motion is typically done by applying the Reynolds-Averaged Navier-Stokes (RANS) equations. These are obtained by decomposing an instantaneous variable $\phi$ into a time-averaged component $\bar{\phi}$ and a fluctuating component $\phi^{\prime}$ as

$$
\phi(t)=\bar{\phi}+\phi^{\prime}(t)
$$

Instantaneous variables in the governing equations are then replaced by this decomposition and the entire equations subsequently time averaged according to the following operation

$$
\bar{\phi}=\frac{1}{T} \int_{-T / 2}^{T / 2} \phi(t) d t
$$


The time average of a time averaged variable is the same, i.e. $\overline{\bar{\phi}}=\bar{\phi}$, and the time average of a fluctuating component is zero, i.e. $\overline{\phi^{\prime}}=0$. The Reynolds-averaged continuity equation, Eq. 14, and the Reynolds-averaged momentum equations, Eq. 15 are obtained by applying Eq. 12 and Eq. 13 to Eq. 8 and 9 yielding [38]

$$
\begin{gathered}
\frac{\partial \bar{u}_{i}}{\partial x_{i}}=0 \\
\rho \bar{u}_{j} \frac{\partial \bar{u}_{i}}{\partial x_{j}}=-\frac{\partial \bar{p}}{\partial x_{i}}+\frac{\partial}{\partial x_{j}}\left(2 \mu \bar{s}_{j i}-\rho \overline{u_{j}^{\prime} u_{i}^{\prime}}\right)
\end{gathered}
$$

where

$$
\bar{s}_{i j}=\frac{1}{2}\left(\frac{\partial \bar{u}_{i}}{\partial x_{j}}+\frac{\partial \bar{u}_{j}}{\partial x_{i}}\right)
$$

Solving the RANS equations thus yields the time averaged properties directly, and therefore the time derivatives have been removed. The fundamental issue with RANS is the introduction of the averaged products of unknown fluctuating components, $\left(-\rho \overline{u_{i}^{\prime} u_{j}^{\prime}}\right)$, stemming from the nonlinear terms, and called Reynolds stresses as their contribution to the flow behavior is similar to that of viscous stresses (represented by the first term in the parenthesis on the right hand side of Eq. 15). The challenge of turbulence modeling is essentially to accurately determine these fluctuating components, and there is still no generally applicable way to do this. Various methods exist, some have shown good results and become more or less frequently used, yet none is always superior the others, only suitable for a moderate number of flow problems.

The general problem to find a way to determine the Reynolds stresses and thereby close the RANS equations is known as the "closure problem". Many of the most frequently used techniques are based on an assumption that the Reynolds stresses, in analogy with the viscous stresses, are linearly related to the velocity gradients of the mean flow. This is known as the Boussinesq hypothesis. The constant of proportionality is called eddy or turbulent viscosity. For the specific Reynolds stresses this relationship is expressed as [38] (p. 106)

$$
-\left(\overline{u_{i}^{\prime} u_{j}^{\prime}}\right)=2 \nu_{t} \bar{s}_{i j}-\frac{2}{3} k \delta_{i j}
$$

where $\nu_{t}$ is the eddy (or turbulent) viscosity, $\delta_{i j}$ is the Kronecker delta, and $k$ the turbulent kinetic energy defined as

$$
k=\frac{1}{2}\left(u_{i}^{\prime} u_{i}^{\prime}\right)
$$

$\delta_{i j}=1$ if $i=j$ otherwise $\delta_{i j}=0$. Eddy viscosity is an invented property, named and used in analogy with the molecular viscosity. The term containing $k$ 
has been added to avoid the sum of the squared normal Reynolds stresses $\left(\overline{u_{i}^{\prime} u_{i}^{\prime}}\right)$, i.e. the turbulent kinetic energy, to be zero, which otherwise would be the case for incompressible flow. Strictly, the last term of Eq. 17 implies isotropic turbulence, i.e. $\overline{u_{1}^{\prime}}=\overline{u_{2}^{\prime}}=\overline{u_{3}^{\prime}}$, and Reynolds shear stresses equal to zero, which is rarely the case in a blood vessel.

Now, the problem is to determine the eddy viscosity, and even for this there are models of different complexity. From simple algebraic expressions, via introduction of one or more transport equations for turbulent properties, to a transport equation for every Reynolds stress. The alternatives with additional transport equations dominate, particularly two-equation models like the $k-\epsilon$ and $k-\omega$ or variants of these. The name refers to the number of additional transport equations that are solved. For the $k-\epsilon$ there is one transport equation for $k$ and one for $\epsilon$, and the eddy viscosity is obtained as [65]

$$
\nu_{t_{k-\epsilon}}=C_{\mu} \frac{k^{2}}{\epsilon}
$$

where $C_{\mu}$ is a model constant. Analogously for the $k-\omega$-model $k$ is obtained from one transport equation and $\omega$ from another, and subsequently used to determine the eddy viscosity.

Somewhat more advanced is the shear stress transport (SST) $k-\omega$ model developed by Menter [66, 67], which essentially utilizes the $k-\omega$ model close to walls and switches to $k-\epsilon$ further out. The transition SST (tSST) is yet an advancement of the $k-\omega$ SST including two additional transport equations for intermittency and for the transition onset criteria, respectively [67-69].

To summarize, in RANS models the influence of all turbulent motion on the mean flow is modeled, and a steady, time-averaged flow field (which most likely differs for different turbulence models) is computed. The steady flow field is simply achieved by adding extra "turbulent" viscosity in the model and thereby damping out all unsteadiness. The disadvantage is the limited applicability of each model; for cardiovascular applications no model has yet shown satisfactory results.

Sometimes the unsteadiness of the flow is just too massive to be appropriately represented by a time averaged flow field. This has led to development of unsteady RANS (URANS) models, where the time derivatives of the Navier-Stokes equations are spared in order to resolve parts of the turbulent scales. The time over which the solution variables is averaged is assumed to be much smaller than the time scales of the resolved motion. Compared to (steady) RANS the turbulent viscosity is somewhat smaller to allow the development of some unsteadiness in the solution. 


\subsubsection{LES}

Large eddy simulation is an unsteady approach intending to resolve the larger, energy containing eddies, while the smaller scales are modeled (as in RANS). The strength of LES over RANS is supposed to lie in the inclusion of some turbulence in the calculations, and compared to URANS the difference is essentially to include "more" turbulence and unsteadiness. LES has turned up as a competitive approach for more general use during the last decade thanks to increased available computer power. The border between resolved and unresolved motion is determined by the size of the cells in the mesh. A scale smaller than the cells of the mesh is modeled and referred to as a sub grid scale (SGS). A spatial filter according to Eq. 19 removes the SGSs from the calculations so that the flow field is represented by the spatial average of the variables in each cell. Similar to the Reynolds decomposition, LES utilizes a decomposition where a variable is split in filtered (cell average) component, $\tilde{\phi}$, and a component representing the fluctuations around this average in the cell, $\phi^{\prime \prime}$.

$$
\tilde{\phi}=\frac{1}{V} \int_{V} \phi(\mathbf{x}) d \mathbf{x}
$$

Comparing this filter operation with the temporal averaging applied for RANS one should note that:

i This is a pure spatial operation, i.e. $\tilde{\phi}$ is still a function of time.

ii $\tilde{\tilde{\phi}} \neq \tilde{\phi}$.

iii $\tilde{\phi^{\prime \prime}} \neq 0$

Applying Eq. 19 to the governing equations and rearranging yields Eq. 20, the filtered continuity equation, and Eq. 21, the filtered momentum equations.

$$
\begin{gathered}
\frac{\partial \tilde{u}_{i}}{\partial x_{i}}=0 \\
\frac{\partial \bar{u}_{i}}{\partial t}+\frac{\partial}{\partial x_{j}}\left(\tilde{u}_{i} \tilde{u}_{j}\right)=-\frac{1}{\rho} \frac{\partial \tilde{p}}{\partial x_{i}}+\frac{\partial}{\partial x_{j}}\left(\nu \frac{\partial \tilde{u}_{i}}{\partial x_{j}}\right)-\frac{\partial \tau_{i j}}{\partial x_{j}} .
\end{gathered}
$$

Similar to RANS where the Reynolds stresses appeared from the non-linear terms, a term of unknowns has also appeared in Eq. 21 (last term on the right hand side). These are referred to as SGS stresses and defined according to Eq. 22. The remaining problem is to determine these terms and thereby close the system of equations. 


$$
\tau_{i j}=\widetilde{u_{i} u_{j}}-\tilde{u}_{i} \tilde{u}_{j}
$$

Again, the Boussinesq hypothesis is utilized, and provides a model for the deviatoric part of the SGS tensor according to Eq. 23, where $\tilde{s}_{i j}$ is the resolved strain rate tensor, Eq. 24, and again the challenge is to determine the coefficient of proportionality, $\nu_{S G S}$, between the SGS stresses and velocity gradients. $\nu_{S G S}$ is known as SGS eddy viscosity.

$$
\begin{gathered}
\tau_{i j}-\frac{1}{3} \tau_{k k} \delta_{i j}=-2 \nu_{S G S} \tilde{s}_{i j}, \\
\tilde{s}_{i j}=\frac{1}{2}\left(\frac{\partial \tilde{u}_{i}}{\partial x_{j}}+\frac{\partial \tilde{u}_{j}}{\partial x_{i}}\right)
\end{gathered}
$$

Throughout the present work the dynamic Smagorinsky model was used [65]. It is based on the original Smagorinsky model, in which the SGS viscosity is obtained as

$$
\nu_{t}=\left(C_{s} \Delta\right)^{2}|\tilde{s}|
$$

where $C_{s}$ is the Smagorinsky constant, $\Delta$ the cubic root of the cell volume, and $|\tilde{s}|=\sqrt{2 \tilde{s}_{i j} \tilde{s}_{i j}}$. Values of $C_{s}$ are typically $0.1-0.2$ depending on the particular problem, however therein is also the shortcoming of the model in that the value of $C_{s}$ tends to vary rather than being just constant. To overcome this Germano et al. developed a dynamic procedure in which the model parameter $C_{s}$ is computed using information from the smallest resolved scales [70]. This information is obtained by introducing a second filter, the test filter, typically twice the size of the ordinary grid filter. Applying the test filter to the already grid-filtered equations extracts the desired information (from the smallest resolved scales). Subsequently Lilly improved the model [71]. In the CFD software Fluent (which was used for most of the simulations in this work), $C_{s}$ is limited from 0 to 0.23 to avoid numerical instability [67].

\subsubsection{Mixed Models}

Between LES and RANS a number of different models that utilize RANS/URANS, and LES in different regions have been suggested. Detached eddy simulation (DES) employs LES in free shear flows away from walls, and RANS in the near wall region [72], whereas other similar hybrid models utilize LES in a smaller region surrounded by a RANS solution (embedded LES). Recently, scale adaptive 
simulation (SAS) and partially averaged Navier-Stokes (PANS) have appeared [7376]. These use some kind of sensor (a variable with a predictable behavior) for unsteadiness in the flow. If this is high the solution is supposed to go unsteady, otherwise it is in steady RANS mode. The potential of the mixed models for biofluid-simulation is still to be investigated, which is beyond the scope of this thesis.

\subsubsection{Resolution and Quality Assessment of LES - General Con- siderations}

The finer mesh the better resolution, and for low Reynolds numbers it is possible to reach the size of the very smallest flow structures. Sometimes, however, a relatively fine resolution, although not completely down to Kolmogorov scales, tempts investigators to refer to the solution as a course DNS, pseudo DNS, or some other type of DNS. In the author's opinion, though, a DNS is a DNS, resolving all scales. With or without SGS modeling anything else (when turbulence is resolved) is a more or less well resolved LES.

To evaluate the resolution for LES is a quite extensive task, and since LES for more general use is a relatively novel technique, clear and undebatable measures and parameters to state mesh independence are not yet established. A well, or at least sufficiently, resolved LES requires that the SGS model appropriately handles the unresolved scales, which inescapably implies that a sufficiently large part of the turbulent scales must be resolved. The question is now how to know that this is the case? To answer, two different regions must be considered: the near wall region and bulk flow or wake region.

\section{Near Wall Resolution}

As long as the flow remains attached to the wall the procedure at walls is rather straight forward, with guidelines regarding the non-dimensional plus units, Eq. 25 Eq. 27.

$$
\begin{gathered}
y^{+}=\frac{u_{\tau} y}{\nu} \\
\Delta x^{+}=\frac{u_{\tau} \Delta x}{\nu} \\
\Delta z^{+}=\frac{u_{\tau} \Delta z}{\nu}
\end{gathered}
$$

where 


$$
\begin{gathered}
u_{\tau}=\sqrt{\frac{\mathrm{WSS}}{\rho}} \\
u^{+}=\frac{u}{u_{\tau}}
\end{gathered}
$$

and $u$ is the velocity (component or magnitude) to normalize, here exemplified by the component in the $x$ direction. To resolve the boundary layer down to the viscous sub layer requires that $y^{+} \leq 1$, and to capture the dynamics in the other directions $\Delta x^{+}$and $\Delta z^{+}$should at least be less than 100 and 30, respectively. Following these guidelines usually ensures appropriate thickness of the first cell layer, and sufficient streamwise and spanwise resolution of the turbulent structures. Together with at least 15-20 cells across the boundary layer one can probably feel comfortable with the near wall modeling unless there are obvious reasons to suspect the opposite. For separated flows (e.g. likely after the constriction in the model in Fig. 2) the plus values do not have the same physical interpretation. Nevertheless, keeping them low improves the reliability, although the over all assessment and previous experience is of even greater value.

\section{Bulk Flow Resolution}

To state sufficient resolution of the bulk flow, and if present in wakes, is a more delicate issue. Mesh independence, which should imply sufficient resolution, can be ensured by conducting simulations with finer meshes for comparison. However, for large cases it might be unaffordable to create and run a finer mesh than "what is believed to be sufficient", and in that case the investigator and the rest of the simulation community must be convinced of the reliability of the results in some other way. Typically the procedure relates to the turbulence theory discussed in Sec. 1.3 in that the assessment focuses on how well expected phenomena are captured by the solution.

According to the name, and as stated above, a LES is intended to simulate (i.e. resolve) the larger eddies of the flow. Hence, to estimate by how many cells in the mesh they are covered would clearly be a measure of the resolution. This information can be obtained from two-point correlations which compare velocity fluctuations at two points separated by a distance $r(r=|\mathbf{r}|)$ according to Eq. 30, see e.g. [38]. In Eq. 30 the correlation is normalized with the root mean square (RMS) values at $\mathbf{r}=0$. (In Eq. 30 Einstein summation is not employed.)

$$
B_{i j}(\mathbf{x}, t ; \mathbf{r})=\frac{1}{u_{i, r m s}(\mathbf{x}, t) u_{j, r m s}(\mathbf{x}, t)} \overline{u_{i}^{\prime}(\mathbf{x}, t) u_{j}^{\prime}(\mathbf{x}+\mathbf{r}, t)}
$$

The velocity signals at points $\mathbf{x}$ and $\mathbf{x}+\mathbf{r}$ will be correlated as long as they are located within the same large structure. Since $B_{i j}$ is normalized it will decrease 
from unity. A reliable $B_{i j}$ requires sufficiently many samples in the velocity signals, meaning that sufficiently many large structure have passed the points.

\subsubsection{Resolution of LES in Constricted Pipe with Dilatation - Present Work}

Figure 9 shows two-point correlations of each velocity component in its respective coordinate direction at $4 \mathrm{D}$ downstream of the stenosis, i.e. in the turbulent region, for $\mathrm{Re}=3000$ in the model in Fig. 18 (a). The abscissa shows the number of cells between the points.

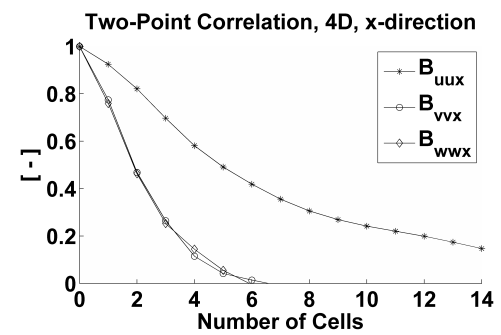

(a)

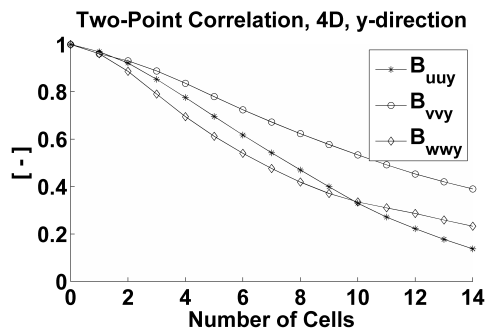

(b)

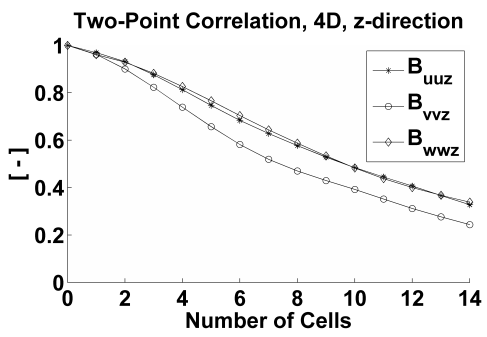

(c)

Figure 9: Two-point correlations of the velocity fluctuations in the (a) $x$-direction, (b) $y$ direction, and (c) $z$-direction for steady flow of $\mathrm{Re}=3000$ and a mesh with $8.9 \mathrm{MC}$. The abscissa shows the number of cells between the points. The correlations remain satisfactory high a for separation of 14 cells in all directions except for the radial components in the axial direction. Tests with finer meshes though revealed this to be of no significance for the results. Hence, the the mesh was considered adequate for the present purpose. 
Exactly how many cells that are required to capture a structure is difficult to say, and possibly it can differ for different flow problems. Intuitively two are too few while 20 seem enough, hence there should be a limit somewhere inbetween. Davidson [77] suggests that the recommended minimum number of cells covering the larger scales should be at least eight for a coarse LES. In Fig. 9 it is seen that with two exceptions all correlations in all directions remain relatively high within 14 cells indicating sufficient resolution. However, the resolution of the radial components in the axial direction seems to be unsatisfactory as decorrelation (below 0.1 ) occurs after 4 or 5 cells. To investigate the significance of this shortcoming a simulation was run with a mesh with considerably higher resolution in the axial direction. Three million additional cells, i.e. about $12 \mathrm{MC}$ in total now resolved the same scales with at least 12 cells. Concerning the flow field, the only noticeable difference was a somewhat earlier jet-breakdown and turbulence onset than for the coarse mesh. The same was also seen with an even more refined (in all parts of the domain) mesh. For the present purpose this was not considered to compromise the results and conclusions, and hence even the course mesh would qualify to use for LES.

Apart from investigating correlations and eddy resolution, turbulent kinetic energy is supposed to decrease proportionally to $\kappa^{-5 / 3}$ in developed turbulence, according to Kolmogorov's theory. This is most easily investigated by studying energy spectra of the velocity fluctuations, Fig. 10. All velocity spectra were nondimensionalized, $E^{*}$, and plotted against a non-dimensional Strouhal number, $N_{S}$, as was done by [44] (who in turn followed previous experimental works).

$$
\begin{aligned}
E^{*} & =\frac{E(f) u_{s t}}{2 \pi d_{s t}} \\
N_{s} & =\frac{2 \pi f d_{s t}}{u_{s t}}
\end{aligned}
$$

$E(f)$ was the energy associated with the frequency $f, u_{s t}$ the cross-sectional average velocity at the stenosis throat, and $d_{s t}$ the diameter at the stenosis throat. 


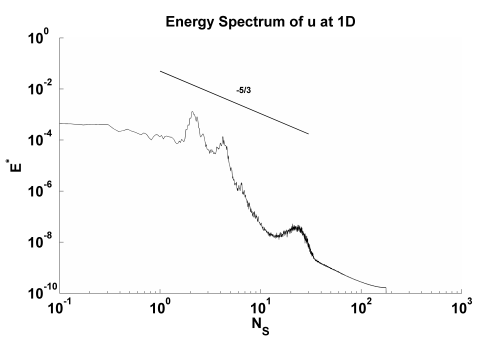

(a)

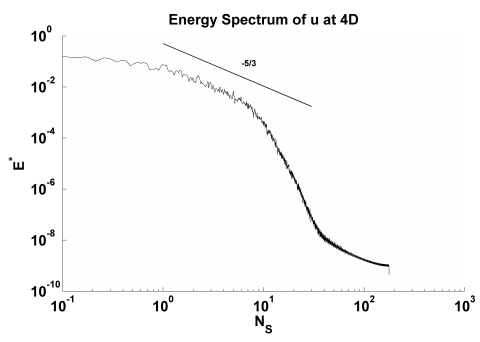

(b)

Figure 10: Non-dimensional energy spectra (according to Eq. 31 and Eq. 32) of the axial velocity fluctuation at (a) $1 \mathrm{D}$ and (b) 4D, for $\mathrm{Re}=3000$ in the model in Fig. 18. Results in analogy with similar DNS findings [44] were found, and the characteristic -5/3-slope appears at 4D.

At 4D the -5/3 slope appears, which indicates that turbulence has developed as expected. The plots show strong similarity with corresponding plots for the straight pipe with stenosis obtained from DNS [44], although the latter were for a lower Reynolds number $(1000)$. The peaks at $1 \mathrm{D}$ can probably be derived to vortex shedding from the shear layer after the constriction. At 4D these vortices were dissolved. Concerning the resolution, however, Davidson [77] found that the frequently used velocity spectrum might indicate sufficient resolution in that expected behaviors, i.e. slopes of the spectrum are found, while two-point correlations indicate that the larger scales are covered by a relatively small number of cells. This suggests that spectra in accordance with expectations are a necessary rather than sufficient indication of the resolution.

The temporal resolution is controlled by the CFL number. Keeping this below unity in the domain ensures that the time step size matches the size of the cells. Typically, a few regions will be limiters, while much of the solution will be overresolved in time.

\subsection{Numerical Settings and Boundary Conditions}

All simulations were conducted with Ansys Fluent (release 13.0 - 14.5) (ANSYS, Inc., Canonsburg, PA, USA), which employs a finite volume method, see Sec. 2.1.1. Diffusive and convective fluxes were discretized using second-order central differencing, and the pressure at a cell face was computed using a discrete continuity balance for a staggered control volume. The pressure-velocity coupling was handled by the fractional-step method [65]. A fully implicit second order scheme was used for the temporal discretization. 
For the stenosed pipe in Fig. 2 Poiseuille flow ${ }^{1}$ was prescribed at the inlet and perturbations generated using a variant of the vortex method [65] were superimposed onto this. The vortex method produces a spatially correlated disturbance field depending on a specified intensity $I_{i n}$, the mesh size, and the time step size. Unphysical numerical oscillations commonly obtained for completely random disturbances that may deteriorate the solution are thus avoided. No-slip was applied at the wall. At the outlet (pressure-outlet) the pressure was fixed and all other variables were extrapolated from the interior cells.

For the CoA-model in Fig. 18 uniform flow was prescribed on a circle in the center covering half of the inlet area, and outside this the velocity was zero. The purpose was to induce a disturbed flow similar to that after the aortic valve. No additional perturbations were added. The walls and outlet were again treated as no-slip and pressure-outlet, respectively.

\subsection{WSS Post-Processing}

In the appended papers, post-processing of WSS aims to identify parameters that can be used for quantification of WSS, and that are relatively easily determined to enable routine use in the clinics. All parameters are presented in the appended papers and summarized in this section.

In paper II instantaneous axial and circumferential WSS, $\mathrm{WSS}_{a x}$ and $\mathrm{WSS}_{\text {circ }}$, respectively, were split into a mean and a fluctuating component (analogously to the Reynolds decomposition) as

$$
\begin{aligned}
\mathrm{WSS}_{a x} & =\overline{\mathrm{WSS}}_{a x}+\mathrm{wss}_{a x}^{\prime} \\
\mathrm{WSS}_{c i r c} & =\overline{\mathrm{WSS}}_{c i r c}+\mathrm{wss}_{c i r c}^{\prime}
\end{aligned}
$$

Instantaneous magnitude, $|\mathbf{W S S}|$, was obtained from the instantaneous axial and circumferential components as

$$
|\mathbf{W S S}|=\sqrt{\mathrm{WSS}_{a x}^{2}+\mathrm{WSS}_{\text {circ }}^{2}}
$$

Both components were monitored every time step from the stenosis to the outlet, and subsequently, the time averaged components and magnitude of $N$ samples were obtained as

$$
\overline{\mathrm{WSS}}_{a x}=\frac{1}{N} \sum_{i=1}^{N} \mathrm{WSS}_{a x, i}
$$

\footnotetext{
${ }^{1}$ Steady, fully developed laminar flow of an incompressible Newtonian fluid in a circular pipe
} 


$$
\overline{\mathrm{WSS}}_{\text {circ }}=\frac{1}{N} \sum_{i=1}^{N} \mathrm{WSS}_{\text {circ }, i}
$$

and

$$
\overline{|\mathbf{W S S}|}=\frac{1}{N} \sum_{i=1}^{N}|\mathbf{W S S}|_{i}
$$

The fluctuations were determined as RMS-values of the differences between instantaneous and time averaged quantity, i.e.

$$
\begin{aligned}
\mathrm{wss}_{a x}^{\prime} & =\sqrt{\frac{1}{N} \sum_{i=1}^{N}\left(\mathrm{WSS}_{a x, i}-\overline{\mathrm{WSS}}_{a x}\right)^{2}} \\
\mathrm{wss}_{c i r c}^{\prime} & =\sqrt{\frac{1}{N} \sum_{i=1}^{N}\left(\mathrm{WSS}_{c i r c, i}-\overline{\mathrm{WSS}}_{c i r c}\right)^{2}}
\end{aligned}
$$

and

$$
|\mathbf{w s s}|^{\prime}=\sqrt{\frac{1}{N} \sum_{i=1}^{N}\left(|\mathbf{W S S}|_{i}-\overline{|\mathbf{W S S}|}\right)^{2}}
$$

When analyzing pulsating flows, it may be of interest to quantify the average load at a certain instant of the cycle. This information is provided by the phase average WSS, PAWSS, defined for any component as:

$$
\text { PAWSS }=\frac{1}{N+1} \sum_{n=0}^{N-1} \operatorname{WSS}(t+n \cdot T)
$$

where $N$ is the number of cardiac cycles, and $T$ the time of each cycle. Frequently occurring in the literature is the time averaged WSS, TAWSS, which is a temporal average during a pulse. Here, TAWSS was based on the PAWSS as a representative pulse and computed as

$$
\text { TAWSS }=\frac{1}{T} \int_{0}^{T} \mid \text { PAWSS } \mid d t
$$

The WSS angle, used for e.g. rose-plots in Paper II and V, is simply obtained from the axial and circumferential components. Another parameter related to WSS oscillations is the oscillatory shear index (OSI) obtained as

$$
\mathrm{OSI}=\frac{1}{2}\left[1-\frac{\left|\int_{0}^{T} \mathbf{W S S} d t\right|}{\int_{0}^{T}|\mathbf{W S S}| d t}\right]
$$





\section{Chapter 3}

\section{Results and Discussion}

\subsection{Biofluid Simulation}

Throughout this work WSS, as a link between hemodynamics and cardiovascular function, has been a key parameter. Initially a study was conducted to evaluate the validity of WSS in blood vessels when obtained under the assumption of HagenPoiseuille flow [14] (i.e. steady, fully developed, laminar flow of an incompressible Newtonian fluid). Since the results of Paper I revealed a velocity profile far from fully developed laminar flow, and therefore asymmetric WSS pattern, the inability of the Hagen-Pouseuille estimations to reasonably predict WSS came as no big surprise. From the beginning, it was thus clear that accurate calculation of arterial WSS in general requires a sufficiently resolved three-dimensional velocity field in the vessel.

The first of the appended papers, and moreover the start of this work, presents the fundamental parts of blood-flow simulations. MRI images were used to create subject specific vessel models, and flow measurements from the same apparatus were used for inlet boundary conditions (and for comparison of simulation results). This constitute the input to subsequent simulations of the blood flow inside the vessel, from which the output is an almost infinite amount of parameters. Today the procedure is routine, at least within the research field.

As the biofluid research progressed, new challenges appeared. Along with the fluid mechanics field in general, turbulent flow got more and more attention, and also became the underlying theme for this dissertation; more specifically, to find and apply a method to accurately simulate turbulent flow in blood vessels and subsequently extract and assess informative parameters. From Paper II the rest of the work is about usage of LES, i.e. a scale resolving simulation technique, for blood flow simulation and quantification of relevant hemodynamic parameters. This chapter summarizes the results from the papers and some additional material 
and comments are added.

\subsection{CFD Simulation of Transitional Arterial Flow}

Paper II is an investigation of the capability of LES to simulate transitional and turbulent flow in blood vessels. The need for this study was identified since RANS models had failed to reproduce experimental observations [55-58] of the flow through the pipe in Fig. 2. In addition, no DNS studies for $\operatorname{Re}>1000$ were found. An important part of the work was to investigate whether artificial perturbations of the velocity profile at the inlet could be used to control the post-stenotic turbulence characteristics, in order to mimic the conditions in various blood vessels.

\subsubsection{Time Averaged and Fluctuating Velocity}

Steady flow of Reynolds numbers 500, 1000 , and 2000 in a pipe with a 75\% reduction of cross sectional area were considered, and results were compared to experiments [55-58] and, for the two lower Reynolds numbers, to DNS predictions [44]. Velocity profiles are shown in Fig. 4, 6, and 8 in Paper II. For the lowest Reynolds number no turbulence developed, even with large disturbances at the inlet.

$\mathrm{Re}=1000$ was an interesting case in that the experiments showed a turbulent post-stenotic flow, while DNS predicted the same flow as completely laminar. No measurements of disturbances at the location of the LES-inlet were reported, but at the stenosis throat the fluctuating axial component was about $2.8 \%$ of the cross-sectional average inlet velocity. The DNS was run without any imposed perturbations.

The LES-results suggested that varying the inlet disturbances was an effective strategy for managing the post-stenotic turbulence in terms of location and extent of the transitional region, Fig. 11 (reproduced from Paper II). To match the experimental observations required very large inlet perturbations, corresponding to about $10 \%$ to $12 \%$ turbulence intensity for both $\mathrm{Re}=1000$ and $\mathrm{Re}=2000$. DNS predictions were perfectly replicated without inlet perturbations, although intermittant unsteadiness (not reported for the DNS) appeared with some regularity (see Paper II for a detailed discussion). This clearly demonstrates the sensitivity and transitional nature of this flow around $\mathrm{Re}=1000$. 


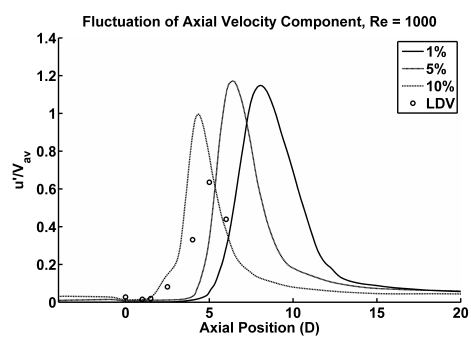

(a)

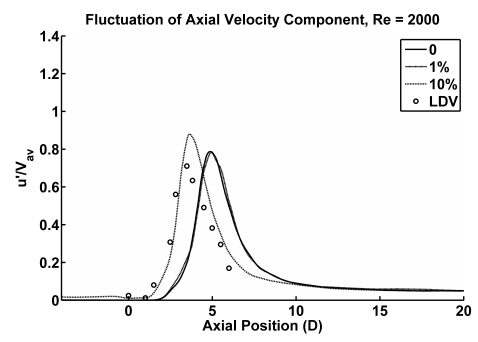

(b)

Figure 11: Root mean square values of the axial velocity along the centerline from LES with different inlet perturbations compared to LDV measurements [57]. The inlet disturbance affects the location and extent of the transitional region. These Fig. 7 and Fig. 11 in Paper II.

Admittedly, $10 \%-12 \%$ intensity is a large disturbance, however, as was also discussed in Paper II, this decreased quickly, and was at the constriction only a few percent. Thus the range of actual perturbations at the stenosis throat, causing the different turbulence characteristics downstream was rather small. In addition the level of disturbances at the throat also depended on the distance from the inlet. This suggests that focus should be on the disturbances at the throat rather than on the amount at the inlet. Based on this, and since the accuracy of the measurements has been questioned previously, e.g. in that Varghese et al. [44] for $\mathrm{Re}=500$ found better agreement between their DNS and the LDV measurements if the DNS model had a $73 \%$ area reduction instead of $75 \%$, no additional efforts were made to find the "perfect" disturbances for this case.

In Paper II it was concluded that a scale resolving approach is necessary and LES is suitable for transitional flows in stenosed pipes, and that addition of inlet perturbations is one suitable tool to control transition in terms of location and extent.

\subsubsection{Energy Spectra}

To further analyze the impact of the inlet perturbations velocity spectra of the flow in the post-stenotic region in the model in Fig. 2 were computed. In accordance with [44] non-dimensional spectra, $E^{*}$, were plotted against a non-dimensional Strouhal number, $N_{S}$, see Eq. 31 and Eq. 32. The spectra for $\operatorname{Re}=1000$ and $\operatorname{Re}=2000$ with $1 \%$ and $10 \%$ disturbance at the inlet are shown in Fig. 12. The lines corresponding to the -5/3-slope (inertial subrange) and -7-slope (dissipative range [47]) are also shown in the figures. 


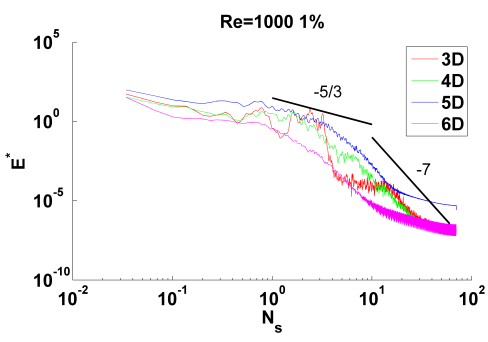

(a)

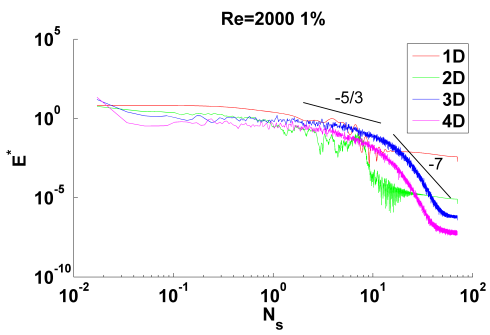

(c)

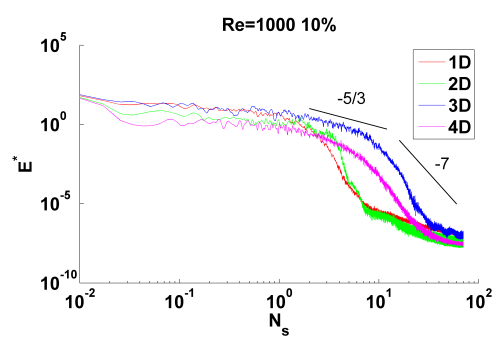

(b)

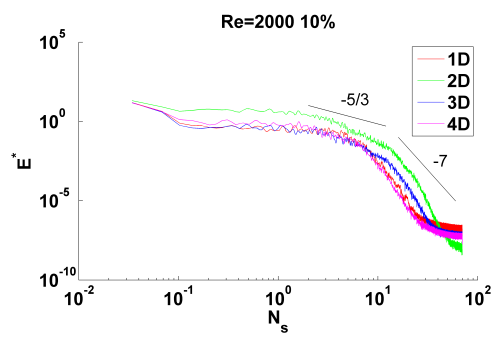

(d)

Figure 12: Spectral energy distribution in the post-stenotic turbulent flow in the geometry in Fig. 2. The diagrams are for different Reynolds numbers and inlet disturbances. Due to later onset of turbulence for $\mathrm{Re}=1000,1 \%$ (a), the spectra are shown at $3 \mathrm{D}, 4 \mathrm{D}, 5 \mathrm{D}$, and $6 \mathrm{D}$, instead of at $1 \mathrm{D}, 2 \mathrm{D}, 3 \mathrm{D}$, and $4 \mathrm{D}$ for the other cases. The $-5 / 3$ slope and the -7 slope indicate the viscous subrange and the dissipating range, respectively.

With large perturbations, for the two studied Reynolds numbers, the turbulence quickly attained a smooth energy distribution for a range of frequencies, with both the inertial subrange and dissipative range discernable. The inertial subrange was relatively small, which was also indicated by the DNS-spectra. Compared to [44] no peaks for lower frequencies were found, suggesting that these perturbations were strong enough to destroy much of the vortex shedding. For the cases with small disturbances there were peaks at lower frequencies in accordance with the DNS results (for $\mathrm{Re}=1000$ ), which indicates that the slight eccentricity affected the stability similarly as the small disturbances.

Note that the spectra for $\mathrm{Re}=1000$ with $1 \%$ perturbations are shown at $3 \mathrm{D}$, $4 \mathrm{D}, 5 \mathrm{D}$, and $6 \mathrm{D}$ (due to the relatively late onset of turbulence), while they for the other cases were computed at 1D, 2D, 3D, and 4D. In all cases the energy eventually decreased in the axial direction, indicating less energy fed into the energy cascade, reduced turbulence, and beginning relaminarization. 


\subsubsection{RANS Modeling}

Several studies comparing RANS-predictions to LDV measurements of stenotic pipe flow have been presented, but the RANS models have so far not successfully predicted the experiments. For comparison some RANS simulations were also conducted within this work.

For $\mathrm{Re}=1000$ standard, realizable, and RNG $k-\epsilon$ all predicted too early onset of turbulence compared to LDV measurements and LES predictions. The differences between the models were marginal. They were relatively insensitive for disturbances at the inlet.

Fig. 13 shows velocity profiles predicted by SST $k-\omega$ and tSST from the stenosis throat and downstream for Reynolds numbers 1000 and 2000 , respectively, compared to LES (highly disturbed, i.e. 10\%). Both the SST $k-\omega$ and tSST were more sensitive to inlet disturbances than the $k-\epsilon$ models. For $\operatorname{Re}=1000$ both predicted earlier jet break down and reatachment than LES and LDV measurements, n.b. even with essentially no disturbances at the inlet.

For $\mathrm{Re}=2000$ the tSST, when run with large perturbations, matched the disturbed LES remarkably well, to the author's knowledge better than any RANS model has done previously. Even for this Reynolds number both SST $k-\omega$ and tSST responded to changed inlet perturbations, although SST $k-\omega$ was always somewhat delayed compared to tSST, LES, and LDV. Some tests were also run with the SAS model, but it behaved completely as a steady RANS without any instabilities, even with large perturbations at the inlet.

Eq. 4 and 5 were used to estimate the Kolmogorov length and time scales from the SST $k-\omega$. For $\operatorname{Re}=2000 \eta=33 \mu \mathrm{m}$ and $\tau=90 \mu \mathrm{s}$, respectively, and for $\mathrm{Re}=3000$ the corresponding values were $25 \mu \mathrm{m}$ and $54 \mu \mathrm{s}$, respectively. Which is comparable to the size of the red blood cells (about $8 \mu \mathrm{m}$ ).

In addition to the conclusions of Paper II it should now be said that at least the more sophisticated tSST RANS model, which is supposed to handle transitional flow, seems to be capable to predict mean flow properties of the stenotic pipe flow reasonably well. 


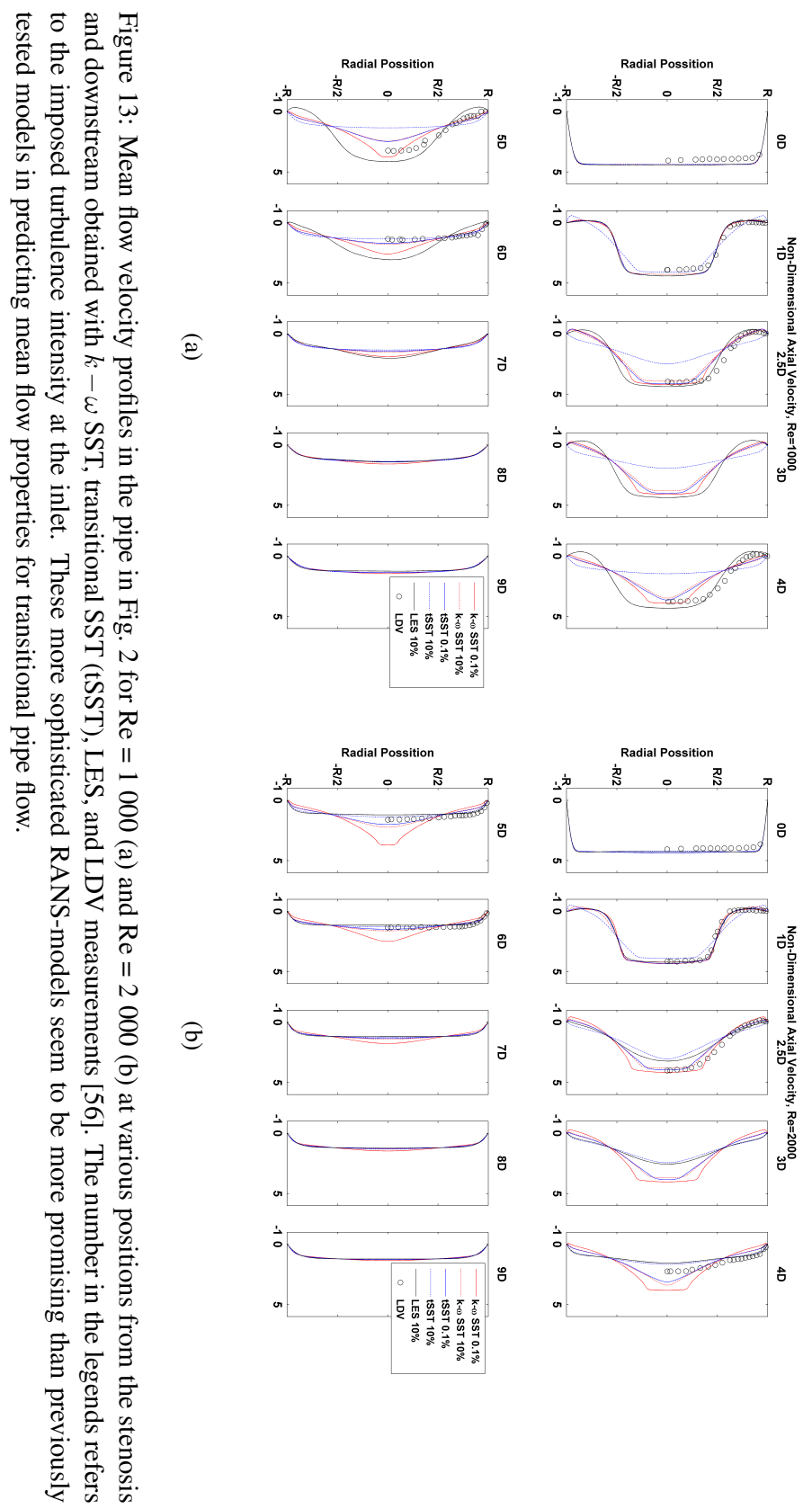




\subsection{WSS in Turbulent Flow}

\subsubsection{Steady Flow in an Axisymmetric Constricted Pipe}

Paper III focuses on estimation and quantification of WSS in steady turbulent flow in the stenotic pipe in Fig. 2. Fig. 14 and Fig. 15 illustrate different ways to present and assess WSS, exemplified for $\mathrm{Re}=2000$. Fig. 14 shows time signals of axial and circumferential WSS at 2, 4, and 6 diameters downstream of the stenosis throat (see Fig. 2). Apart from the scales not resolved by the LES this would be the time-resolved WSS-signal sensed by the endothelial cells on the luminal surface. Clearly WSS was affected by the turbulence.

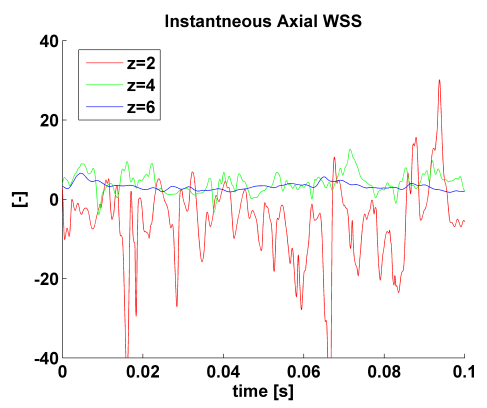

(a)

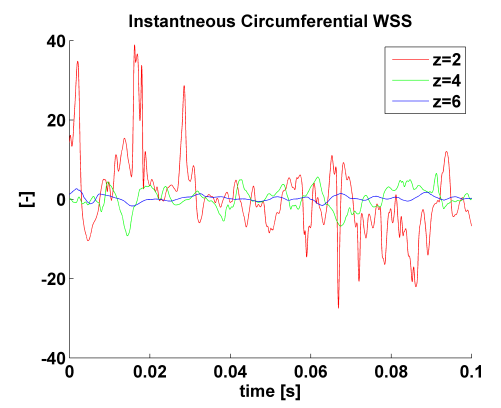

(b)

Figure 14: Instantaneous axial WSS (a) and circumferential WSS (b) at three different locations for $\operatorname{Re}=2000$ in the pipe in Fig. 2. The turbulence is seen to affect the WSS, although the oscillations are not as intense as those of the centerline velocity, see Fig. 4.

\section{Time Averaged and Fluctuating WSS}

Although Fig. 14 contains some qualitative information, practically it is not very useful as it merely shows a behavior, and lacks general quantification. In addition WSS is only showed at three points on the entire surface. In Fig. 15 (a) the axial and circumferential WSS have been decomposed into a time averaged component $\overline{\text { WSS }}$ and a fluctuating component wss' according to Eq. 33 and 34. The values were calculated every diameter from the stenosis throat and downstream. Interestingly, compared to Fig. 11, maximum WSS fluctuation occurred upstream of the maximum oscillations along the centerline. Fig. 15 (b) shows the time average of the WSS magnitude and its fluctuation together with WSS magnitude extracted from a steady RANS (in this case a $k-\omega$ SST). 


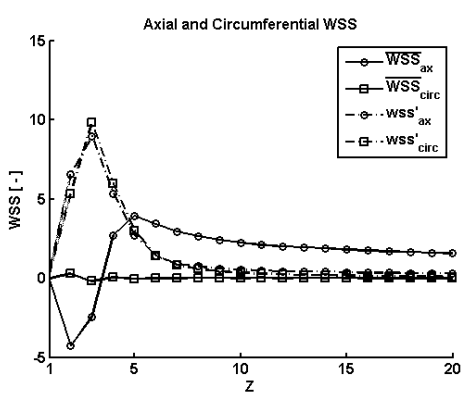

(a)

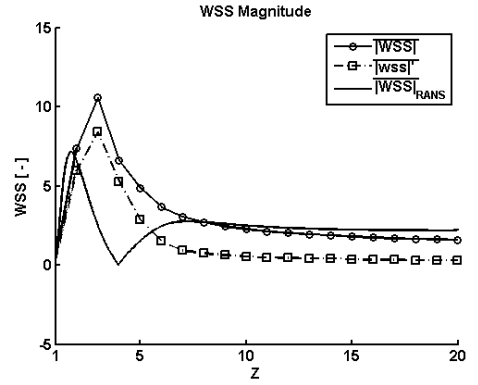

(b)

Figure 15: (a) Time average and fluctuating part of the axial and circumferential WSS for $\mathrm{Re}=2000$ in the pipe in Fig. 2. A recirculation region is revealed by negative axial WSS. Note the large fluctuations in the post-stenotic region. (b) Time average WSS magnitude and its fluctuation compared with WSS magnitude extracted from a steady RANS. Depending on how the magnitude is determined, the results might be very different. These plots are from Fig. 2 and Fig. 3 in Paper III.

To summarize the discussion in Paper III, the sign of the axial component revealed a recirculation zone after the stenosis, which surrounded a jet, whose break-down was associated with transition to turbulence and large fluctuating components. It should be noted that the fluctuations in the axial and circumferential direction were approximately equal in size. As expected, the time average of the circumferential component was zero whereas the axial went from being negative in the recirculation zone to positive after reattachment. Consequently, endothelial cells would be exposed to considerable fluctuations in both directions, axially in a stretched state and circumferentially in a relaxed state.

In Fig. 15 (b), somewhat contradictory, WSS magnitude as predicted by LES indicated a maximum while the RANS results showed a minimum (in fact zero WSS) - at almost the same location. The magnitude was relatively high at this location, however, as revealed in Fig. 13 and Fig. 14 in Paper II, so was also the angular variation in this region. Hence, the components will change sign frequently resulting in time averages of these equal to zero. Care should thus be taken when evaluating WSS to avoid misinterpretations of the results.

As described above fluctuations of WSS reached a maximum somewhat upstream to the position where the velocity fluctuations were as largest, suggesting some difference in development between centerline turbulence and wall turbulence. To investigate this and to further assess how turbulence affects WSS, energy spectra of the axial WSS were computed in the post-stenotic region, and are shown in Fig. 16. 


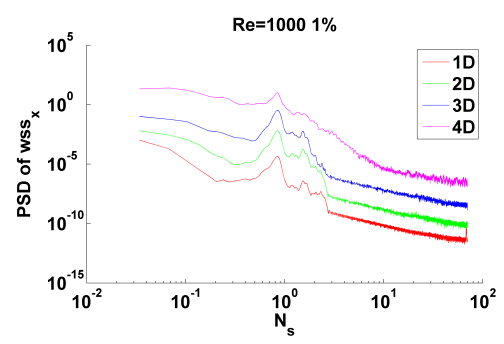

(a)

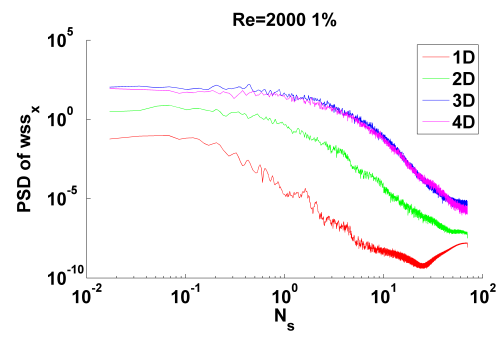

(c)

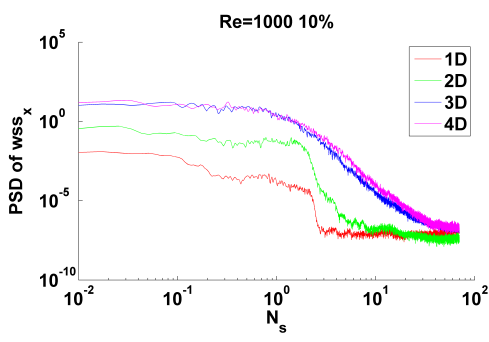

(b)

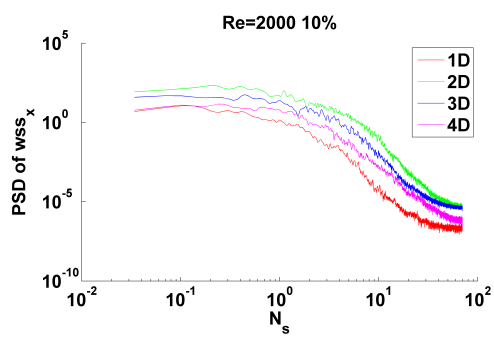

(d)

Figure 16: Power spectral density of axial WSS in the post-stenotic region of the pipe in Fig. 2 for $\operatorname{Re}=1000(a, b)$ and $\operatorname{Re}=2000(c, d)$ with $1 \%(a, c)$ and and $10 \%(b, d)$ intensity at the inlets.

Similar to the velocity spectra in Fig 12 (b) and (d) the spectral energy distribution of WSS developed relatively quickly, and consequently endothelial cells would not be affected by oscillations of any particular frequency, but rather of a continuous range. For $\operatorname{Re}=2000$ with small disturbances, Fig. 16 (c), there was a clear development of the spectral energy distribution, and at 2D there was a peak around $N_{s}=35$, possibly corresponding to one or several of the peaks between $N_{s}=30$ and $N_{s}=80$ seen in the spectra of axial centerline velocity in Fig. 12 (c). For $\operatorname{Re}=1000$ with $1 \%$ perturbations some peaks developed at $1 \mathrm{D}$, i.e. imediately after the constriction. These attenuated only slowly further downstream. Consequently, in a longer transitional region, seen for the lower Reynolds number with moderate disturbances, endotheilial cells would be affected by shearing loads with one or a few distinct frequencies, whereas higher Reynolds numbers and stronger disturbances promote shearing loads of a smooth range of frequencies. 


\subsubsection{WSS in Pulsating Flow}

Normal blood flow is often considered laminar [3]. However, in Paper IV LES is applied for flow in a healthy subject specific human aorta, and according to Fig. 5 and 6 in the paper the situation is not necessarily that simple. Diastolic flow in the human aorta exhibits a very complex pattern including jets, flow-reversal, recirculation, and generally disturbed motion. Probably not turbulent in a sense of after a transition, but yet sufficiently disturbed to be disqualified as a laminar flow.

The figures particularly identify suspicious flow patterns along the inner curvature of the arch and at the branches. Then, Fig. 7 in the Paper IV, repeated in Fig. 17 here, identifies precisely these regions to distinguish in that both OSI and TAWSS were comparably high. The black regions in Fig. 17 (b) were found inside the red box in Fig. 17 (a). These results are of particular importance in that they constitute a bridge between the medical and technical side of the work.

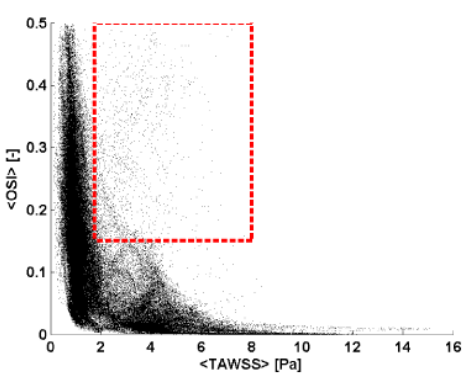

(a)

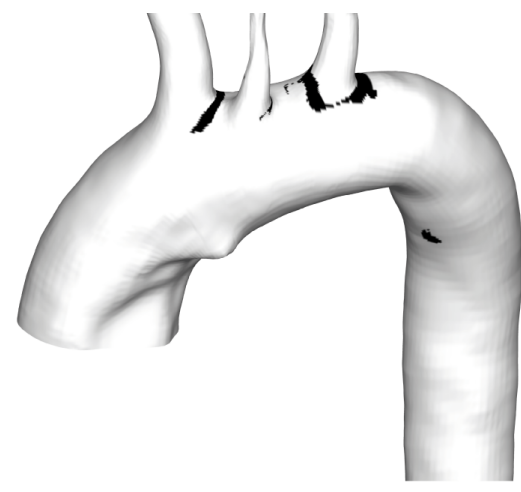

(b)

Figure 17: (a) OSI vs. TAWSS (both based on phase average values). The red rectangle marks points at which OSI and TAWSS are relatively high. When mapped back onto the arterial surface (b) these points were localized to the branches and to the recirculation zone on the inner curvature of the arch.

Decomposition of WSS was again utilized in Paper IV, now the WSS signal was split into an average pulsating part (due to the periodic pulsations) and a fluctuating part quantifying the deviation from the periodic pulsations. As seen in Fig. 9-12 of Paper IV the spatial variation (between the points) as well as the temporal variation at each point were significant. In addition, the interphasial variation at each time point, sometimes comparable to the size of the TAWSS, indicated a uniqueness of each pulse, which was also emphasized by Mittal et al. [47]. It is 
also worth to highlight the uniqueness of each branch, which becomes obvious when points $\mathrm{P} 1$ to $\mathrm{P} 4$ are compared.

\subsection{Towards Intervention Planning}

The predictive capability of CFD simulations was addressed in Paper V, by evaluating pulsating flow in an idealized model of an aorta with coarctation and poststenotic dilatation. The flow was studied before and after a possible CoA repair, but when the dilatation was left untreated. WSS and other hemodynamic parameters known to affect the cardiovascular function were investigated before and after treatment. The geometries are shown in Fig. 18.

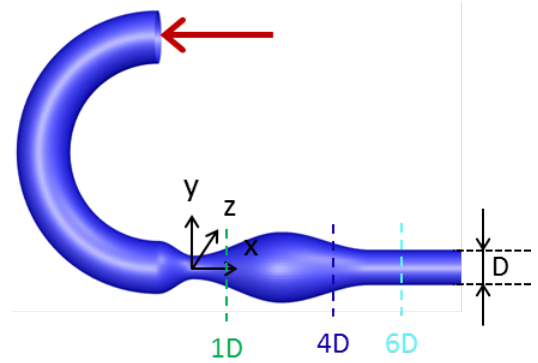

(a)

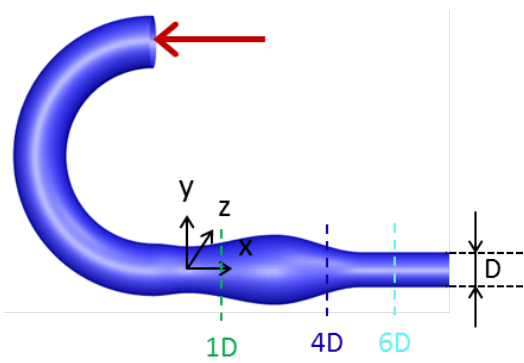

(b)

Figure 18: (a) Generic model of a human aorta with a coarctation and a post-stenotic dilatation. After CoA repair (b) the remaining reduction of cross sectional area was $21 \%$. In both models the coordinate system had its origin in the middle of the throat.

In Paper $\mathrm{V}$ it was shown that leaving the dilatation untreated, deteriorate the chance of success with the intervention. Fig. 19 shows TKE based on fluctuations around the phase average velocity obtained from 50 consecutive pulses. One can note the different characteristics between the first three (1D-3D) and the last three (4D-6D), in that the TKE in the first points reached a maximum relatively late in systole, whereas the maximum level is reached sooner (close to peak systole) at $4 \mathrm{D}$ to $6 \mathrm{D}$, suggesting that the turbulence in a sense propagates upstream. Clearly, the TKE was reduced considerably after CoA correction, but was still not completely eliminated. Further investigations on this topic should be conducted. Recent works have demonstrated that TKE can be measured using MRI [41, 42], and since this has not been possible with WSS the clinical value of TKE is potentially high. 


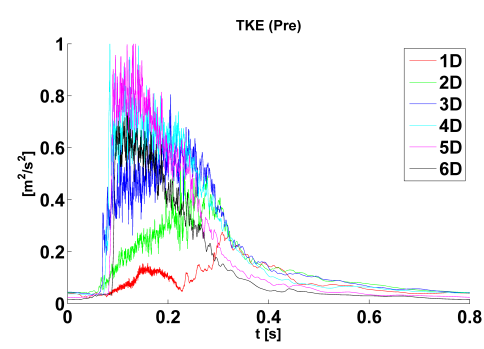

(a)

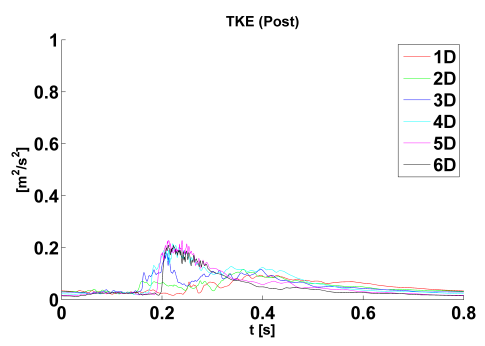

(b)

Figure 19: Turbulent kinetic energy (TKE) computed from 50 consecutive pulses before (a) and after (b) CoA repair.

Fig. 20 shows axial and circumferential PAWSS during the first half of the pulse at $z=-\mathrm{R}, y=-\mathrm{R}$, and $y=\mathrm{R}$ computed from 50 consecutive pulses. The values at $z=-\mathrm{R}$ were excluded due to symmetry over time, as was diastolic PAWSS $(t>0.4 \mathrm{~s})$, which was comparably small. First thing to note was that all asymmetry caused by the arch was essentially destroyed by the constriction, particularly for the axial PAWSS. Consequently, the circumferential component was essentially associated with the three-dimensionality caused by turbulence. It became prominent in the convergent part of the dilatation, at about $0.05 \mathrm{~s}$, i.e. at onset of turbulence and spatially after jet break down.

The tendency was similar for the phase fluctuation, i.e. the RMS deviation form the phase average, see Fig. 21. Similarly to the results in Paper III the axial and circumferential fluctuations were roughly equal, while the average components differed in size. CoA repair with a slight remaining reduction of crosssectional area made the asymmetry marginally more pronounced, Fig. 22 . The fluctuating nature of WSS remained, Fig. 23, suggesting that the conditions for further recovery were not optimal. This was also supported by the plots of angular variation (Fig. 7 and 8) in Paper V (where the tendency after repair even was towards WSS acting more in opposite directions rather than in a limited range around one direction). The oscillatory shear index (OSI) in fact indicated somewhat more fluctuations within a smaller region after this repair.

Paper V thus demonstrated a possible use of flow simulation for intervention planing, as well as suggested that care should be taken to restore the entire geometry, including the dilatation, at $\mathrm{CoA}$ repair. 

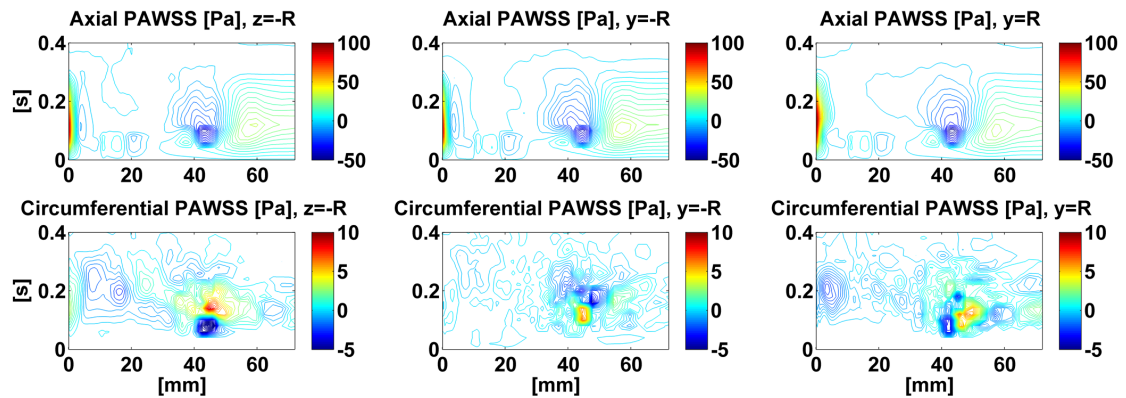

Circumferential PAWSS [Pa], $y=R$

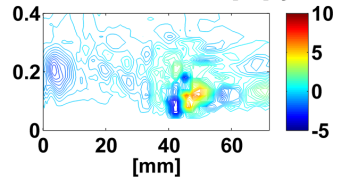

Figure 20: Axial (upper row) and circumferential (lower row) PAWSS before CoA repair along three lines: $z=-\mathrm{R}, y=-\mathrm{R}$, and $y=\mathrm{R}$ (see Fig. 18) during systole.
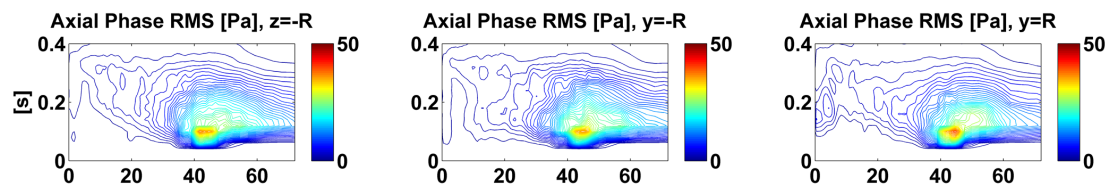

Circumferential Phase RMS [Pa], z=-R
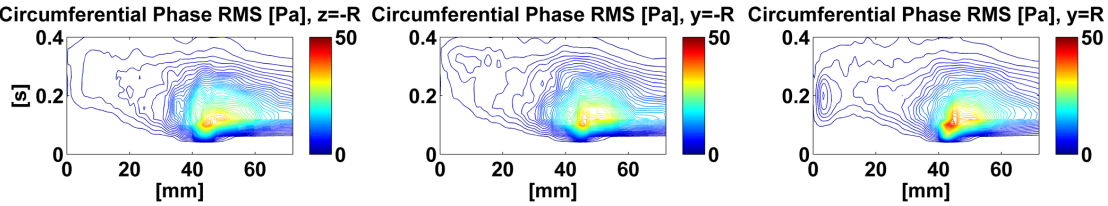

Figure 21: Fluctuations around the axial (upper row) and circumferential (lower row) PAWSS before CoA repair along three lines: $z=-\mathrm{R}, y=-\mathrm{R}$, and $y=\mathrm{R}$ (see Fig. 18) during systole. 

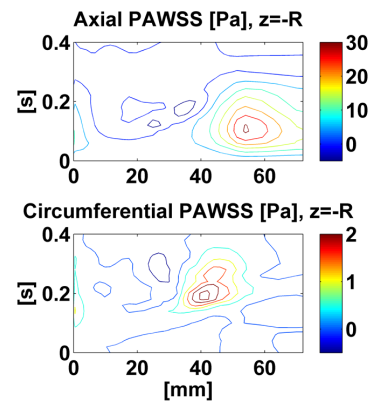
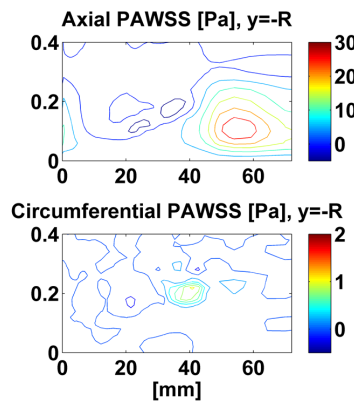

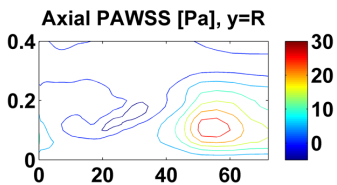

Circumferential PAWSS [Pa], $y=R$

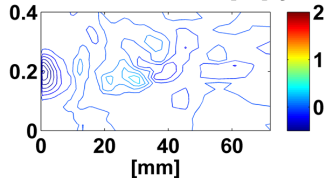

Figure 22: Axial (upper row) and circumferential (lower row) PAWSS after CoA repair along three lines: $z=-\mathrm{R}, y=-\mathrm{R}$, and $y=\mathrm{R}$ (see Fig. 18) during systole.
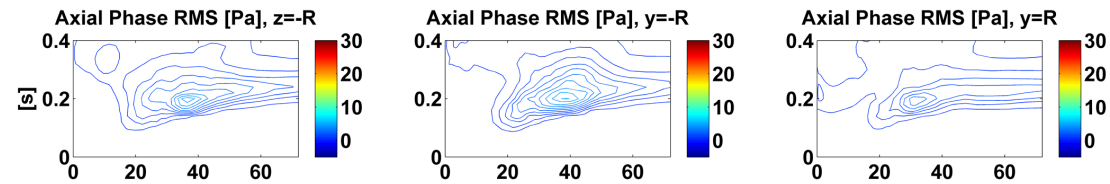

Circumferential Phase RMS [Pa], $z=-$
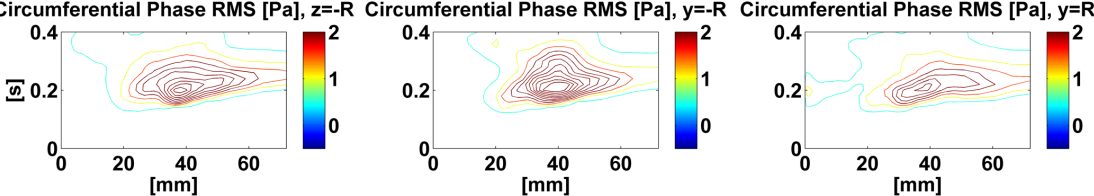

Figure 23: Fluctuations around the axial (upper row) and circumferential (lower row) PAWSS after CoA repair along three lines: $z=-\mathrm{R}, y=-\mathrm{R}$, and $y=\mathrm{R}$ (see Fig. 18) during systole. 


\subsection{Outlook}

At the start of this work, CFD simulation of flow in subject specific vessel models based on MRI measurements was a novel technique, but within the academia it has now become a matter of routine.

Even though there is a method to handle complex arterial flows, it can be improved. The interaction between non-Newtonian effects and turbulence needs to be investigated, fluid-structure interaction is a necessary extension, already utilized in several studies, as is the inclusion of the solid constituents of the blood, i.e. multi phase flow, etc.

Naturally, the next step should be to enable routine use in clinics. This requires larger studies with normals and patients, both before and after treatment in order to verify the findings, also during longer periods. 



\section{Chapter 4}

\section{Review of Appended Papers}

\section{Paper I}

Feasibility of Patient Specific Aortic Blood Flow CFD Simulations, Johan Svensson, Roland Gårdhagen, Einar Heiberg, Tino Ebbers, Dan Loyd, Toste Länne, Matts Karlsson, Proceedings of MICCAI (Medical Image Computing and ComputerAssisted Intervention), Copenhagen Denmark, ISBN 3-540-44707-5, 2-4 October, 2006.

The paper presents a semi automatic and easily executable procedure for conducting CFD simulations of blood flow in two subject specific vessel models obtained from MRI, and with measured velocity as boundary condition at the inlet located in the ascending aorta. Velocity obtained from the simulations was compared with MRI measurements in a cross section in the descending aorta, and showed satisfactory agreement.

Author Contributions: Svensson and Gårdhagen did the simulations and post-processing of the results. Heiberg developed the segmentation algorithm, and Ebbers was responsible for MRI measurements. Loyd and Karlsson contributed with experience from previous biofluid work, and with comments during the writing. Länne contributed with physiological experience and comments during the writing.

\section{Paper II}

Large Eddy Simulation of Stenotic Flow for Wall Shear Stress Estimation Validation and Application, Roland Gårdhagen, Jonas Lantz, Fredrik Carlsson, Matts Karlsson, WSEAS Transactions on Biology and Biomedicine, 2011, Vol. 8, 86-101. 
This paper contains a thorough study on LES for transitional, non-pulsating and pulsating flow in a stenotic pipe at physiologic Reynolds numbers. The range of Reynolds numbers for which scale resolving simulations of pipe flow were conducted was extended. Validation was done against DNS (for $\operatorname{Re}=1000$ ) and LDV measurements, and special attention was directed on using inlet disturbances to control the post-stenotic turbulence. The oscillatory behavior of WSS was addressed by studying the angular variation at different locations along the pipe. WSS was strongly affected by the turbulence and varied considerably in magnitude and direction along the pipe. Terms in the WSS gradient that are normally neglected were found to be very large.

Author Contributions: Gårdhagen did the simulations, some of the postprocessing, and most of the writing. Lantz did some post processing and writing. Carlsson advised and assisted during the simulations and writing. Karlsson initiated the work, and guided through the investigation and writing.

\section{Paper III}

Quantifying Turbulent Wall Shear Stress in a Stenosed Pipe Using Large Eddy Simulation, Roland Gårdhagen, Jonas Lantz, Fredrik Carlsson, Matts Karlsson, Journal of Biomechanical Engineering, 2010, Vol. 132.

Results from a scale resolving technique were used to quantify and assess WSS in turbulent flow in a new way: by a time average and a fluctuating component, analogous to the Reynolds decomposition. Three regions of different WSS patterns were discovered: the recirculation zone, reattachment, and after reattachment. The fluctuations were generally large, and reached maximum at the reattachment where they were of the same size as the average. Before was a recirculation zone with backward WSS and after reattachment WSS was mainly oriented in the main flow direction.

Author Contributions: Gårdhagen did the simulations, some of the postprocessing, and most of the writing. Lantz did some post processing and writing. Carlsson advised and assisted during the simulations and writing. Karlsson initiated the work, and guided through the investigation and writing.

\section{Paper IV}

Quantifying turbulent wall shear stress in a subject specific human aorta using large eddy simulation, Jonas Lantz, Roland Gårdhagen, Matts Karlsson, Medical Engineering and Physics,2011, Vol.34, 1139-1148.

This work extended the method from Paper III to a subject specific vessel 
model (based on MRI measurements), and showed the physiological relevance of the work. Regions of high OSI as well as TAWSS were found at the branches from the arch, i.e. common sites for atherosclerotic lesions. Furthermore, phase averages and the RMS deviation from these during 50 pulses showed large spatial and temporal variations in the aorta.

Author Contributions: Lantz did the simulations, post processing, and most of the writing. Gårdhagen contributed to the analysis and assessment of the results and to the writing. Karlsson guided throughout the work.

\section{Paper V}

Large Eddy Simulation of Pulsating Flow Before and After CoA Repair CFD for Intervention Planning, Roland Gårdhagen, Fredrik Carlsson, Matts Karlsson, Submitted for publication.

The methods introduced in the previous papers were applied for assessment of CoA repair from a fluid dynamical aspect. Known risk factors for cardiovascular disease including WSS and turbulence related parameters were investigated before and after removal of the constriction but with a post-stenotic dilatation left untreated. The remaining dilatation was found to deteriorate the result, and several of the risk factors prevailed suggesting that the anatomy should be completely restored.

Author Contributions: Gårdhagen did the simulations, post-processing, and writing. Carlsson advised and assisted during the simulations and writing. Karlsson guided through the work. 



\section{Bibliography}

[1] Paulsen D.F. Histology\& Cell Biology: Examination \& Board Review, chapter 11 General Features of the Circulatory System, pages Electronic Resource, Retrieved June 17, 2013 from http://www.accessmedicine.com/content.aspx?aID=57093947. McGrawHill Education, 5 edition, 2010.

[2] G. J. Tortora and S. R. Grabowski. Principles of Anatomy and Physiology. John Wiley \& Sons, Inc., 9th edition, 2000.

[3] D. N. Ku. Blood flow in arteries. Annu. Rev. Fluid Mech., 29:399-434, 1997.

[4] W. Nichols and M. O'Rurke. McDonald's Blood Flow in Arteries. Edward Arnold, 3rd edition, 1990.

[5] M. A. Gimbrone. Vascular endothelium, hemodynamic forces, and atherogenesis. Am. J. Pathol., 155(1):1-5, Jul 1999.

[6] V. L. Roger, A. S. Go, D. M. Lloyd-Jones, E. J. Benjamin, J. D. Berry, W. B. Borden, D. M. Bravata, S. Dai, E. S. Ford, C. S. Fox, H. J. Fullerton, C. Gillespie, S. M. Hailpern, J. A. Heit, V. J. Howard, B. M. Kissela, S. J. Kittner, D. T. Lackland, J. H. Lichtman, L. D. Lisabeth, D. M. Makuc, G. M. Marcus, A. Marelli, D. B. Matchar, C. S. Moy, D. Mozaffarian, M. E. Mussolino, G. Nichol, N. P. Paynter, E. Z. Soliman, P. D. Sorlie, N. Sotoodehnia, T. N. Turan, S. S. Virani, N. D. Wong, D. Woo, and M. B. Turner. Heart disease and stroke statistics-2012 update: a report from the American Heart Association. Circulation, 125(1):e2-e220, Jan 2012.

[7] R. Ross and J. A. Glomset. The pathogenesis of atherosclerosis (first of two parts). N. Engl. J. Med., 295(7):369-377, Aug 1976.

[8] R. Ross and J. A. Glomset. The pathogenesis of atherosclerosis (second of two parts). N. Engl. J. Med., 295(8):420-425, Aug 1976.

[9] C. K. Glass and J. L. Witztum. Atherosclerosis. the road ahead. Cell, 104(4):503-516, Feb 2001. 
[10] A. Lusis. Atherosclerosis. Nature, 407:233-241, 2000.

[11] P. Assemat and K. Hourigan. Evolution and rupture of vulnerable plaques: a review of mechanical effects. ChronoPhysiology and Therapy, 3:23-40, 2013.

[12] D. C. Wilcox. Basic Fluid Mechanics. DCW Industries, 2nd edition, 2003.

[13] F. M. White. Viscous Fluid Flow. McGraw Hill, 2nd edition, 1991.

[14] R. Gardhagen, J. Renner, T. Länne, and M. Karlsson. Subject specific wall shear stress in th human thoracic aorta. WSEAS Transactions on Biology and Biomedicine, 3:609-614, 2006.

[15] C. G. Caro, J. M. Fitz-Gerald, and R. C. Schroter. Arterial wall shear and distribution of early atheroma in man. Nature, 223(5211):1159-1160, 1969.

[16] P. F. Davies. Mechanisms involved in endothelial responses to hemodynamic forces. Atherosclerosis, 131 Suppl:S15-17, Jun 1997.

[17] P. A. VanderLaan, C. A. Reardon, and G. S. Getz. Site specificity of atherosclerosis: site-selective responses to atherosclerotic modulators. Arterioscler. Thromb. Vasc. Biol., 24(1):12-22, Jan 2004.

[18] K. S. Cunningham and A. I. Gotlieb. The role of shear stress in the pathogenesis of atherosclerosis. Lab. Invest., 85(1):9-23, Jan 2005.

[19] A. Feintuch, P. Ruengsakulrach, A. Lin, J. Zhang, Y. Q. Zhou, J. Bishop, L. Davidson, D. Courtman, F. S. Foster, D. A. Steinman, R. M. Henkelman, and C. R. Ethier. Hemodynamics in the mouse aortic arch as assessed by MRI, ultrasound, and numerical modeling. Am. J. Physiol. Heart Circ. Physiol., 292(2):H884-892, Feb 2007.

[20] H. C. Groen, F. J. Gijsen, A. van der Lugt, M. S. Ferguson, T. S. Hatsukami, A. F. van der Steen, C. Yuan, and J. J. Wentzel. Plaque rupture in the carotid artery is localized at the high shear stress region: a case report. Stroke, 38(8):2379-2381, Aug 2007.

[21] M. A. Gimbrone and G. Garcia-Cardena. Vascular endothelium, hemodynamics, and the pathobiology of atherosclerosis. Cardiovasc. Pathol., 22(1):9-15, 2013.

[22] F. Gijsen, A. van der Giessen, A. van der Steen, and J. Wentzel. Shear stress and advanced atherosclerosis in human coronary arteries. $J$ Biomech, 46(2):240-247, Jan 2013. 
[23] D. N. Ku, D. P. Giddens, C. K. Zarins, and S. Glagov. Pulsatile flow and atherosclerosis in the human carotid bifurcation. Positive correlation between plaque location and low oscillating shear stress. Arteriosclerosis, 5(3):293-302, 1985.

[24] H. S. Bassiouny, C. K. Zarins, M. H. Kadowaki, and S. Glagov. Hemodynamic stress and experimental aortoiliac atherosclerosis. J. Vasc. Surg., 19(3):426-434, 1994.

[25] C. Carallo, C. Irace, A. Pujia, M. S. De Franceschi, A. Crescenzo, C. Motti, C. Cortese, P. L. Mattioli, and A. Gnasso. Evaluation of common carotid hemodynamic forces. Relations with wall thickening. Hypertension, 34(2):217-221, 1999.

[26] M. Bonert, R. L. Leask, J. Butany, C. R. Ethier, J. G. Myers, K. W. Johnston, and M. Ojha. The relationship between wall shear stress distributions and intimal thickening in the human abdominal aorta. Biomed Eng Online, 2, 2003.

[27] C. Irace, C. Cortese, E. Fiaschi, C. Carallo, E. Farinaro, and A. Gnasso. Wall shear stress is associated with intima-media thickness and carotid atherosclerosis in subjects at low coronary heart disease risk. Stroke, 35(2):464-468, 2004.

[28] J. Suo, D. E. Ferrara, D. Sorescu, R. E. Guldberg, W. R. Taylor, and D. P. Giddens. Hemodynamic shear stresses in mouse aortas: implications for atherogenesis. Arterioscler. Thromb. Vasc. Biol., 27(2):346-351, 2007.

[29] J. J. Wentzel, R. Krams, J. C. Schuurbiers, J. A. Oomen, J. Kloet, W. J. van Der Giessen, P. W. Serruys, and C. J. Slager. Relationship between neointimal thickness and shear stress after wallstent implantation in human coronary arteries. Circulation, 103(13):1740-1745, 2001.

[30] A. Merino, M. Cohen, J. J. Badimon, V. Fuster, and L. Badimon. Synergistic action of severe wall injury and shear forces on thrombus formation in arterial stenosis: Definition of a thrombotic shear rate threshold. JACC, 24(4):1091-1907, 1994.

[31] K. S. Sakariassen, P. A. Holme, U. Orvim, R. M. Barstad, N. O. Solum, and F. R. Brosstad. Shear-induced platelet activation and platelet microparticle formation in native human blood. Thromb. Res., 92(6 Suppl 2):33-41, 1998.

[32] P. D. Stein and H. N. Sabbah. Measured turbulence and its effect on thrombus formation. Circ. Res., 35(4):608-614, Oct 1974. 
[33] J. Mathieu and J. Scott. An Introduction to Turbulent Flow. Cambridge University Press, 2000.

[34] L. F. Richardson. Weather prediction by numerical process. Camebridge university press, 2nd edition, 1922.

[35] S. B. Pope. Turbulent Flow. Cambridge University Press, 2005.

[36] M.A. Green, C.W. Rowley, and G. Haller. Detection of lagrangian coherent structures in three-dimensional turbulence. J. Fluid Mech., 572:111 - 20.

[37] J.C.R. Hunt, A.A. Wray, and P. Moin. Eddies, streams, and convergence zones in turbulent flows. In Center for Turbuelnce Research Proceedings of the Summer Program 1988, pages 193 - 208, 1988.

[38] D. C. Wilcox. Turbulence Modeling for CFD. DCW Industries, 2nd edition, 2004.

[39] P. S. Bernard and J. M. Wallace. Turbulent Flow Analysis, Measurement, and Prediction. John Wiley \& Sons, Inc., 2002.

[40] P. Dyverfeldt, R. Gardhagen, A. Sigfridsson, M. Karlsson, and T. Ebbers. On MRI turbulence quantification. Magn Reson Imaging, 27(7):913-922, Sep 2009.

[41] P. Dyverfeldt, M. D. Hope, E. E. Tseng, and D. Saloner. Magnetic resonance measurement of turbulent kinetic energy for the estimation of irreversible pressure loss in aortic stenosis. JACC Cardiovasc Imaging, 6(1):64-71, Jan 2013.

[42] J. Lantz, T. Ebbers, J. Engvall, and M. Karlsson. Numerical and experimental assessment of turbulent kinetic energy in an aortic coarctation. J Biomech, In press, 2013.

[43] S. Petersson, P. Dyverfeldt, and T. Ebbers. Assessment of the accuracy of MRI wall shear stress estimation using numerical simulations. J Magn Reson Imaging, 36(1):128-138, Jul 2012.

[44] S. S. Varghese, S. H. Frankel, and P. F. Fischer. Direct numerical simulation of stenotic flows. part 1. steady flow. Journal of Fluid Mechanics, 582:253 $-280,2007$.

[45] S. S. Varghese, S. H. Frankel, and P.1 F. Fischer. Direct numerical simulation of stenotic flows. part 2. pulsatile flow. Journal of Fluid Mechanics, 582:281 $-318,2007$. 
[46] S. E. Lee, S. W. Lee, P. F. Fischer, H. S. Bassiouny, and F. Loth. Direct numerical simulation of transitional flow in a stenosed carotid bifurcation. $J$ Biomech, 41(11):2551-2561, Aug 2008.

[47] R. Mittal, S.P. Simmons, and F. Najjar. Numerical study of pulsatile flow in a constricted channel. Journal of Fluid Mechanics, 485:337 - 78, 2003.

[48] S. J. Sherwin and H. M. Blackburn. Three-dimensional instabilities and transition of steady and pulsatile axisymmetric stenotic flows. J. Fluid Mech., 533:297-327, 2005.

[49] S. S. Varghese and S. H. Frankel. Numerical modeling of pulsatile turbulent flow in stenotic vessels. J. Biomech. Eng., 125(4):445-460, 2003.

[50] J. Ryval, A. G. Stratman, and D. A. Steinman. Two-equation turbulence modeling of pulsatile flow in a stenosed tube. J. Biomech. Eng., 126:625635, 2004.

[51] J. Banks and N. W. Bressloff. Turbulence modeling in three-dimensional stenosed arterial bifurcations. J. Biomech. Eng., 129(1):40-50, 2007.

[52] M. C. Paul, M. M. Molla, and G. Roditi. Large-eddy simulation of pulsatile blood flow. Med. Eng. Phys, 31:153-159, 2009.

[53] R. Mittal, S. P. Simmons, and H. S. Udaykumar. Application of large-eddy simulation to the study of pulsatile flow in a modeled arterial stenosis. $J$. Biomech. Eng., 123:325-332, 2001.

[54] J. Lantz, J. Renner, and M. Karlsson. Wall shear stress in a subject specific human aorta - influence of fluid-structure interaction. Int. J.Appl. Mech. (Singapore), 3(4):759 - 78, 2011/12/.

[55] M. D. Desphande and D. P. Giddens. Turbulence measurements in a constricted tube. J. Fluid. Mech., 97:65-89, 1980.

[56] S. A. Ahmed and D. P. Giddens. Velocity measurements in steady flow through axisymmetric stenoses at moderate reynolds numbers. J. Biomechanics, 16(7):505-516, 1983.

[57] S. A. Ahmed and D. P. Giddens. Flow disturbance measurements through a constricted tube at moderate reynolds numbers. J. Biomech., 16(12):955963, 1983.

[58] S. A. Ahmed and D. P. Giddens. Pulsatile poststenotic flow studies with laser doppler anemometry. J. Biomech, 17(9):695-705, 1984. 
[59] M. Markl, P. J. Kilner, and T. Ebbers. Comprehensive 4D velocity mapping of the heart and great vessels by cardiovascular magnetic resonance. $J$ Cardiovasc Magn Reson, 13:7, 2011.

[60] A. Arzani, P. Dyverfeldt, T. Ebbers, and S. C. Shadden. In vivo validation of numerical prediction for turbulence intensity in an aortic coarctation. Ann Biomed Eng., 40(4):860-70, 2012.

[61] J F Ladisa, C A Taylor, and J A Feinstein. Aortic coarctation: Recent developments in experimental and computational methods to assess treatments for this simple condition. Prog Pediatr Cardiol, 30(1):45-49, 2010.

[62] J. S. Coogan, F. P. Chan, C. A. Taylor, and J. A. Feinstein. Computational fluid dynamic simulations of aortic coarctation comparing the effects of surgical- and stent-based treatments on aortic compliance and ventricular workload. Catheter Cardiovasc Interv, 77(5):680-691, Apr 2011.

[63] J. F. LaDisa, R. J. Dholakia, C. A. Figueroa, I. E. Vignon-Clementel, F. P. Chan, M. M. Samyn, J. R. Cava, C. A. Taylor, and J. A. Feinstein. Computational simulations demonstrate altered wall shear stress in aortic coarctation patients treated by resection with end-to-end anastomosis. Congenit Heart Dis, 6(5):432-443, 2011.

[64] A. Menon, D. C. Wendell, H. Wang, T. J. Eddinger, J. M. Toth, R. J. Dholakia, P. M. Larsen, E. S. Jensen, and LaDisa Jr. J. F. A coupled experimental and computational approach to quantify deleterious hemodynamics, vascular alterations, and mechanisms of long-term morbidity in response to aortic coarctation. Journal of Pharmacological and Toxicological Methods, 65:18$28,2012$.

[65] ANSYS, Inc. ANSYS FLUENT Theory Guide, October 2012. Release 14.5.

[66] F. R. Menter. Two-equation Eddy-Viscosity Turbulence M]odels flor Engineering Applications. AIAA Jounal, 31(8):1598-1605, 1994.

[67] FLUENT14.5 User's Guide, October 2012.

[68] R.B. Langtry, F.R. Menter, S.R. Likki, Y.B. Suzen, P.G. Huang, and S. Volker. A correlation-based transition model using local variables-part ii: test cases and industrial applications. Trans. ASME, J.Turbomach. (USA), 128(3):423 - 34, 2006/07/.

[69] F.R. Menter, R.B. Langtry, S.R. Likki, Y.B. Suzen, P.G. Huang, and S. Volker. A correlation-based transition model using local variables - part i: Model formulation. Journal of Turbomachinery, 128(3):413 - 422, 2006. 
[70] M. Germano, U. Piomelli, P. Moin, and W.H. Cabot. A dynamic subgridscale eddy viscosity model. Physics of Fluids A (Fluid Dynamics), 3(7):1760 $-5,1991 / 07 /$.

[71] D.K. Lilly. A proposed modification of the germano subgrid-scale closure method. Physics of Fluids A (Fluid Dynamics), 4(3):633 - 5, 1992/03/.

[72] Philippe R. Spalart. Detached-eddy simulation. Annual Review of Fluid Mechanics, 41:181 - 202, 2009.

[73] F.R. Menter and Y. Egorov. A scale-adaptive simulation model using twoequation models. In 43rd AIAA Aerospace Sciences Meeting and ExhibitMeeting Papers, pages 271 - 283, 2005.

[74] F.R. Menter and Y. Egorov. The scale-adaptive simulation method for unsteady turbulent flow predictions. part 1: Theory and model description. Flow, Turbulence and Combustion, 85(1):113 - 138, 2010.

[75] Y. Egorov, F.R. Menter, R. Lechner, and D. Cokljat. The scale-adaptive simulation method for unsteady turbulent flow predictions. part 2: application to complex flows. Flow, Turbulence and Combustion, 85(1):139 - 65, 2010/07/.

[76] S. S. Girimaji. Partially-averaged navier-stokes model for turbulence: A reynolds-averaged navier-stokes to direct numerical simulation bridging method. Journal of Applied Mechanics, Transactions ASME, 73(3):413 421, 2006.

[77] L. Davidson. Large eddy simulations: how to evaluate resolution. International Journal of Heat and Fluid Flow, 30(5):1016 - 25, 2009/10/. 